\title{
Una mirada al problema del derecho de los sujetos y grupos desaventajados de especial protección en Colombia y la apuesta por una necesaria fundamentación teórica desde las teorías contemporáneas de la justicia*
}

\author{
A Look to the Problem of the Right of the Subjects and Groups \\ Disadvantageous of Special Protection in Colombia and the Bet for \\ a Necessary Theoretical Substantiation from the Contemporary \\ Theories of the Justice \\ Uma olhada ao problema do direito dos sujeitos e grupos em desvantagem \\ de especial proteção na Colômbia e a aposta por uma necessária \\ fundamentação teórica desde as teorias contemporâneas da justiça
}

\author{
Holmedo Peláez Grisales ${ }^{*}$
}

FECHA DE RECEPCIÓN: 22 DE AGOSTO DE 2014. FeCHA DE ACEPTACIÓN: 13 DE OCTUBRE DE 2014

Doi: dx.doi.org/10.12804/esj17.01.2014.04

Para citar este artículo: Peláez Grisales, H. (2015). Una mirada al problema del derecho de los sujetos y grupos desaventajados de especial protección en Colombia y la apuesta por una necesaria fundamentación teórica desde las teorías contemporáneas de la justicia. Estudios Socio-Jurídicos, 17(1), 125-168. Doi: dx.doi.org/10.12804/esj 17.01.2014.04

\section{RESUMEN}

Este artículo aborda el problema dogmático-jurídico de los sujetos y grupos de especial protección en el derecho colombiano y se centra en desarrollar lo que postula como la principal cuestión problemática que debe enfrentar el estudio de la especial protección; esto es, la falta de una reflexión teórica sobre la desconexión existente entre el derecho y la justicia que imposibilita construir un adecuado derecho justo para dicha materia, y en ese orden se apuesta por defender teóricamente la relación necesaria que debe operar entre ellos y se

* Artículo de investigación resultado del proyecto doctoral titulado: Sujetos y grupos desaventajados de especial protección en Colombia, el cual se viene adelantando en la Facultad de Jurisprudencia, Universidad del Rosario, Bogotá, Colombia.

** Abogado. Magíster en Derecho Privado. Docente investigador de la Escuela de Derecho y Ciencias Políticas la Universidad Pontificia Bolivariana, Medellín, Colombia. Estudiante de Doctorado en Derecho y profesor de la Facultad de Jurisprudencia de la Universidad del Rosario, Bogotá, Colombia. Correo electrónico: holmedo.pelaez@upb.edu.co; peláez.holmedo@urosario.edu.co 
propone, por consiguiente, una debida fundamentación teórica desde las más importantes teorías contemporáneas de la justicia para acoger la tesis de la pluralidad de significados de la justicia dentro del derecho de la especial protección. Así, el texto inicia, en primer lugar, dando cuenta del problema general en la materia a partir de las críticas, insuficiencias y omisiones del legislador, el Ejecutivo y los jueces en el orden jurídico; en segundo lugar, afronta la premisa teórica de la relación necesaria entre el derecho y la justicia tejiendo un vínculo entre las más incluyentes teorías del derecho y de la justicia; para finalmente, en tercer lugar, argumentar la propuesta de fundamentación teórica de la justicia en el núcleo del derecho de la especial protección.

Palabras clave: Sujetos y grupos de especial protección, teorías del derecho, teorías de la justicia, principios de justicia.

\section{ABSTRACT}

This article discusses the dogmatic-legal problem of subjects and special protection in Colombian law groups and focuses on developing what postulated as the main problematic issue facing the study of special protection; that is, the lack of a theoretical reflection on the existing disconnection between law and justice which makes it impossible to build a proper just right for that matter and; in that order, are committed to defend theoretically the necessary relationship which must operate among them and proposes, therefore, a proper theoretical foundation from the most important contemporary theories of Justice to accept the thesis of the plurality of meanings of justice within the right of special protection. Thus, the text begins, a first, realizing the general problem in the matter made up criticisms, inadequacies and omissions of the legislature, the executive and the judges in the legal order; Secondly, it faces the theoretical premise of the necessary relationship between law and justice weaving a link between the more inclusive theories of law and justice; to finally, in a third moment, argue the proposal of theoretical foundation of Justice in the heart of the right to special protection.

Key words: Individuals and groups of special protection, theories of law, theories of justice, principles of justice.

\section{RESUMO}

Este artigo aborda o problema dogmático-jurídico dos sujeitos e grupos de especial proteção no direito colombiano e se centra em desenvolver o que postula como a principal questão problemática que deve enfrentar o estudo da especial proteção; isto é, a falta de uma reflexão teórica sobre a desconexão existente entre o direito e a justiça que impossibilita construir um adequado direito justo para dita matéria e, nessa ordem, se aposta por defender teoricamente a relação necessária que deve operar entre eles e se propõe, por conseguinte, uma devida fundamentação teórica desde as mais importantes teorias contemporâneas da justiça para acolher a tese da pluralidade de significados da justiça dentro do direito da especial proteção. Assim então, o texto inicia, em primeiro lugar, dando conta do problema geral na matéria a partir das críticas, insuficiências e omissões do legislador, o executivo e os juízes na ordem jurídica; no segundo lugar, se afronta a premissa teórica da relação necessária entre o direito e a justiça tecendo um vínculo entre as mais inclusivas teorias do direito e da justiça, para finalmente, em um terceiro momento, argumentar a proposta de fundamentação teórica da justiça no núcleo do direito da especial proteção.

Palavras-chave: Sujeitos e grupos de especial proteção, teorias do direito, teorias da justiça, princípios de justiça. 


\section{Introducción}

El indebido tratamiento del objeto jurídico de la especial protección es un problema trascendental histórico no resuelto por el derecho colombiano que impide la materialización, la garantía y la satisfacción de los derechos humanos, fundamentales y básicos entre los denominados sujetos y grupos de especial protección. ${ }^{1}$

Esta afirmación es el punto de partida de la pesquisa, que se dirige a describir las distintas variables que participan en la construcción de este problema para adentrarse en la principal cuestión problemática que enfrenta la especial protección; esto es, la falta de una reflexión teórica sobre la desconexión existente entre el derecho y la justicia que impide un derecho justo en dicha materia y, en ese orden, llega a su objetivo fundamental de proponer una debida fundamentación teórica desde las más importantes teorías contemporáneas de la justicia en el corazón del derecho de la especial protección.

En este sentido, el artículo aborda la pregunta por el objeto de estudio problemático de los sujetos y grupos de especial protección en Colombia, para lo cual identifica las causas que le han dado origen a la protección reforzada, hace una descripción y clasificación de estos sujetos y grupos y plantea las variables que han dado lugar al problema sustancial de la insuficiente "protección" que aquellos reciben del discurso del legislador, el Ejecutivo y los jueces. A partir de allí, se sostiene que en el derecho estatal colombiano no existe un real objeto jurídico de especial protección; por lo tanto, se advierte la necesidad de construir este objeto jurídico teniendo en cuenta la relación necesaria entre el derecho y la justicia, la cual se sustenta

1 La distinción de la titularidad de especial protección entre sujetos y grupos, que en la mayoría de los otros autores se omite, es necesario resaltarla por diferentes razones, entre ellas, primero, porque el derecho debe reconocer tanto la particularidad de los sujetos como su identidad colectiva; de lo contrario, se implantaría una universalidad excluyente de la pluralidad de identidades de estos sujetos. Aquí vale referenciar a Hans Lindal, cuando cita a Paul Ricoeur, en lo referente a la identidad como mismidad y la individualidad colectiva, que no pueden ser desconocidas en el campo del reconocimiento de los derechos (Lindahl, 2007). Segundo, porque la acción principal de la especial protección, esto es, la acción de tutela, permite que en ella sea titular un sujeto individual o plural, sin necesidad de que sea interpuesta por un grupo. De hecho, en la práctica, la mayoría de las veces, los sujetos y no los grupos apelan a la tutela de la especial protección. Y, tercero, porque la misma Corte Constitucional colombiana ha utilizado el término sujetos o grupos de especial protección indiferentemente en sus providencias. 
en una adecuada fundamentación teórica que comprenda, en cada caso, los distintos significados que la justicia debe personificar en el contenido del derecho de la especial protección.

El problema refiere, además, que la materia está difuminada en un discurso aparente, único y formal del Estado que desconoce la diversidad de discursos no estatales, provenientes de los sujetos que regula, quienes luchan por el poder de definición de las justas circunstancias de especial protección que deberían ser protegidas, pero que, en últimas, no resultan reconocidas y ni garantizadas por el derecho. ${ }^{2}$

El artículo, en su inicio, se concentra en destacar los problemas dogmático-jurídicos ${ }^{3}$ de la especial protección, empezando por sostener que el legislador se ha mostrado incapaz de producir un discurso normativo claro, expreso, exigible, organizado, articulado, actualizado y adecuado para la pluralidad de sujetos o grupos de especial protección ${ }^{4}$ para dar a

2 El ordenamiento jurídico colombiano adhiere la categoría jurídica de especial protección, en sentido de derecho positivo, mediante sus normas constitucionales (especialmente el artículo 13 superior) y, de forma específica, respecto de cada sujeto, en la jurisprudencia de la Corte Constitucional y en alguna parte de su legislación. Este discurso ha sido construido de forma vertical, homogéneo y generalizado desde las instituciones estatales y ha dejado de lado los discursos no estatales, heterogéneos y particulares, según la pluralidad de los sujetos y grupos y sus necesidades. Esto responde a que nuestro derecho ha sido construido en el esquema de la tradición de la cultura jurídica contemporánea del positivismo jurídico kelseniano, que se aleja del sentido común de la comunidad lingüística, como lo sostiene Diego Eduardo López Medina (2008, pp. 5-13). En este orden, también el derecho de la especial protección resulta cuestionado desde una visión teóricosociológica del derecho como la de Michel Foucault, la cual sostiene que el derecho aparece como una línea muy delgada dentro de los distintos discursos que regulan el comportamiento social, es decir, es uno más de los lenguajes por los que pasan las relaciones sociales. En este sentido, no solo existen los discursos estatales respecto del derecho de los sujetos de especial protección, sino que también concurren otros discursos no estatales que, por lo general, se encuentran oscurecidos o subordinados a los primeros, como ocurre en el caso colombiano (Hunt y Wickham, 1994). Balakrishnan (2008), con razón, señala que la regla de derecho está limitada por el contexto histórico y político y que el ordenamiento jurídico estatal formal es solo uno de muchos órdenes jurídicos coexistentes. Por tanto, como lo señala Twining (2003), se deben ampliar esos límites hacia la perspectiva del pluralismo jurídico y superar el discurso individualista metodológico, según el cual las reglas son representaciones, ideas, conceptos que representan -como un mapa- el terreno y los obstáculos que nos confrontan en el mundo externo, ya que esto deja por fuera las actuaciones dialógicas [que no siempre son coherentes y que construyen distintos discursol.

3 En este sentido, conforme con el objeto del artículo, el estudio no comprende un abordaje empírico-sociológico de la problemática. Su alcance es de carácter dogmático-jurídico contrastado con algunas de las más importantes teorías de la justicia que han sido estudiadas más en el ámbito de la filosofía política.

4 De acuerdo con la base de datos LexBase, no existe regulación legal específica referida al término sujetos o grupos de especial protección o sobre circunstancias de especial protección; por lo tanto, fue necesario hacer una búsqueda a partir de cada uno de los ya identificados en la Constitución Política y en la jurisprudencia de la Corte Constitucional colombiana como sujetos de especial 

justas en cada caso.

Así mismo, expone que, por otro lado, el Ejecutivo adopta formas normativas $^{5}$ para la implementación de políticas públicas que se enfrentan a dificultades que también impiden un tratamiento adecuado como la falta de una reglamentación ordenada, coherente, sistemática, permanente, publica, socializada, generalizada para todos los entes territoriales, exigible y que cuente con la participación de los sujetos y grupos de especial protección.

Del mismo modo, los jueces hacen parte del problema, por cuanto sus decisiones judiciales ${ }^{6}$ sobre la especial protección adolecen de dispersión, desorganización, superproducción, aplicabilidad solo al caso concreto, tienen problemas de exigibilidad, gozan de un lenguaje demasiado técnico y difícil de entender y apropiar por los sujetos de especial protección y son vistas como una vía contramayoritaria que coloca en riesgo la democracia. Al tiempo, los sujetos de especial protección no cuentan con una vía judicial principal ${ }^{7}$ y clara para demandar a través de un procedimiento y una acción especial estos asuntos.

protección. Así, se halló, cuantitativamente, que la legislación supera las 1743 leyes al respecto. Encontrado en: http://www.lexbase.biz/normas/leyes/buscadorenleyes/niños, niñas, adolescentes, juventudes, adulto mayor, tercera edad, mujeres, madres cabeza de familia, mujeres en estado de embarazo, indigenas, gitanos, negritudes, afrocolombianos, campesinos, discapacitados, invalidez, enfermos, mendigos, indigentes, damnificados, desplazados, desaparecidos, refugiados, extranjeros, etcétera. No obstante, sobre el término genérico especial protección figuran tan solo 40 leyes al respecto en el mismo buscador.

5 Entre otras disposiciones como acuerdos, ordenanzas, resoluciones, reglamentos y circulares que exceden la producción normativa de la rama Ejecutiva, pueden cifrarse como ejemplo solo en Colombia 69 decretos que aplican para todos los órdenes territoriales. Encontrado en: http://www. lexbase.biz/normas/decretos/buscadorendecretos/especialprotección

6 Al respecto se hallaron 1916 decisiones, entre las cuales se encuentran 9 sentencias de unificación, 117 sentencias de constitucionalidad, 1635 sentencias de tutela y 155 autos constitucionales en los cuales la Corte Constitucional se ha pronunciado sobre la especial protección. Encontrado en: http://www.lexbase.biz/jurisprudencia/corteconstitucional/buscadorencorteconstitucional/sujetosdeespecialprotección

7 El mecanismo de la acción de tutela es la vía común a la que han recurrido los sujetos y grupos para demandar una especial protección; no obstante, esta es una acción excepcional o subsidiaria, esto es, el artículo 86 de la Constitución Política señala que esta es procedente para la protección inmediata de los derechos fundamentales y que solo procederá cuando el afectado no disponga de otro medio de defensa judicial, salvo que aquella se utilice como mecanismo transitorio para evitar un perjuicio irremediable. En este caso, si bien la especial protección tiene fundamento en el capítulo de los derechos fundamentales, en el artículo 13 superior referido al derecho fundamental de la igualdad, es en el capítulo de los derechos económicos, sociales y culturales donde se encuentran mayores fundamentos y demandas de especial protección por los individuos y grupos en circunstancias especiales y es frente a estos derechos que el ordenamiento ha dispuesto no con- 
Bajo este discurso dominante del Estado, el problema de fondo se vuelve más complejo; en primer lugar, porque el Estado, al intentar generar una imagen defensora de los derechos humanos, vende la idea de un debido trato a los sujetos de especial protección, pero no lo cumple; ${ }^{8}$ en segundo lugar, porque dentro del Estado existen diferentes discursos sobre la protección de dichos sujetos y grupos que no siempre corresponden con sus necesidades, $y$, en tercer lugar, porque entre las autoridades legislativas, judiciales y administrativas no hay una articulación y colaboración armónica que aborde el problema con justicia.

En este orden, el artículo avanza hacia la tesis de que existe un problema más de fondo de orden teórico respecto de los derechos especiales que incide de manera determinante en su materialización, esto es, el derecho colombiano está edificado en teorías tradicionales dominantes de corte positivista que excluyen o aceptan solo de manera contingente, pero no necesaria, la relación entre el derecho y la justicia, lo que ha permitido a través del derecho formal y práctico mantener el statu quo de dichos sujetos y la justificación del derecho estatal para no responder a sus demandas de justicia o hacerlo solo de forma aparente y discursiva.

Lo anterior ha llevado a afirmar que existe una ausencia de fundamentación teórica adecuada, que impide una teoría de los derechos especiales de los sujetos y grupos de especial protección, en la medida en que el derecho colombiano no está comprometido con la justicia, porque la con-

ceder acciones por considerarlos meras normas programáticas de carácter prestacional no exigibles mediante mecanismos judiciales. No obstante, la Corte Constitucional ha dispuesto que estos son tutelables solo de manera excepcional, pues no existe un consenso generalizado. Esta discusión puede verse, entre muchas otras sentencias, en la T-597-1993; T-373-1998 y en las sentencias T-597-1993, 373 -1998, T-585-2006, tal y como bien lo ha destacado el Semillero de Investigación del grupo de Derechos Humanos de la Facultad de Jurisprudencia de la Universidad del Rosario, al referirse a la Naturaleza Jurídica de los Derechos Económicos, Sociales y Culturales (Cortés, 2007, p. 131). Lo anterior es problemático porque es una restricción innegable de acceso a la justicia para estos sujetos y grupos: primero, porque no cuentan con una acción principal; segundo, porque la acción subsidiaria de la tutela es de carácter excepcional, y, tercero, porque el derecho de especial protección no ha sido definido como un derecho autónomo, sino que está ligado al derecho fundamental de la igualdad y, en otros casos, a los derechos económicos, sociales y culturales, lo que genera serias dificultades para su ejercicio, protección y exigibilidad.

8 Esto puede evidenciarse a partir de las cifras de superproducción normativa expedida por el legislador y los entes de la rama Ejecutiva y por la jurisprudencia de la Corte Constitucional, relacionada anteriormente, y la adopción del sistema universal de protección de los derechos humanos a la cual se ha comprometido Colombia, que en la realidad es cuestionada por un contexto permanente de violación de derechos humanos y de reproducción de un trato indebido de los sujetos y grupos que merecen especial protección. 
sidera algo contingente, que no necesariamente siempre está presente, y en ese sentido lo justo en la especial protección se vuelve algo dúctil a los intereses del Estado.

Este problema ha llevado a la necesidad de entrar en la discusión teórica de la vinculatoriedad o no de la justicia al concepto del derecho. Allí el punto de partida ha sido la teoría hartiana, por cuanto su autor ha sido uno de los más influyentes del positivismo jurídico, corriente imperante del derecho moderno, que ha trascendido a nuestros días y quien a través de sus escritos se encargó de una manera determinante de desentrañar los fundamentos del concepto del derecho, el cual terminó por concebir en una fórmula de unión de reglas primarias y secundarias. Desde dicho referente se cuestiona su teoría, ya que este planteó un concepto del derecho sin identificarlo necesariamente con el concepto de la justicia, lo que no resulta adecuado para la garantía de la materialización de los derechos de los sujetos y grupos de especial protección (Hart, 1941, p. 102).

La tesis que se defiende, por el contrario, de cara a una teoría de los derechos especiales, es que el derecho, en un Estado moderno, debe incluir la justicia como uno de sus elementos conceptuales necesarios que le proporciona la mejor explicación de sus rasgos característicos, pues se explica como su fundamento moral y, a la vez, como su argumento funcional, en tanto contenido mínimo y criterio interpretativo de corrección del sistema jurídico a través del cual se pretende alcanzar el sentido correcto del derecho.

En el escrito se muestra esa relación entre el problema de los sujetos y grupos de especial protección, con la indebida concepción teórica del derecho que se tiene dentro del Estado colombiano; dicha discusión se aproxima desde Hart hacia otros teóricos como Joseph Raz, Fernando Atria, Wilfrid Waluchow, Ronald Dworkin y Robert Alexy, con el fin de confrontar sus teorías y plasmar cómo ha sido el tratamiento del problema de la relación necesaria entre el derecho y la justicia, pasando por diferentes posturas: la exclusión, la inclusión contingente y la inclusión necesaria, posición última que se defiende y que abre la necesidad de entender el derecho y la justicia como conceptos interpretativos conceptual y funcionalmente ligados, que garantizan una adecuada base teórica del derecho en el marco de los sujetos y grupos de especial protección. 
A partir de allí, el estudio avanza más allá; no se queda en sustentar que el problema de la especial protección está anclado a la ausencia de una teoría del derecho adecuada, sino que esa omisión de la relación necesaria entre el derecho y la justicia en la base del derecho colombiano ha generado una falta de fundamentación teórica de la justicia y una incertidumbre sobre lo justo dentro del derecho en general, en particular en el derecho de los sujetos y grupos de especial protección.

Esa omisión ha llevado al desconocimiento de la pluralidad de enfoques teóricos y significados de la justicia, que deben ser tenidos en cuenta en esa relación con el derecho, ya que el uso eventual de la justicia en ordenamiento es tenido como un significado único de carácter formal y estatal y como un instrumento de poder del Estado para mantener la regla general del statu quo, los privilegios en unos y la dominación sobre otros, lo que se convierte en un foco principal de la problemática del objeto jurídico de la especial protección.

Lo anterior lleva a plantear la necesidad de llenar este vacío teórico que existe en el derecho sobre qué es lo justo en materia de especial protección y defender la tesis de la pluralidad de significados de la justicia para los sujetos y grupos de especial protección en el marco de su relación necesaria con el derecho colombiano.

En este sentido, se abordan diversos contenidos de justicia a la luz de las reconocidas teorías contemporáneas de la justicia de cara al objeto jurídico de la especial protección; entre las cuales se destacan las expuestas por John Stuart Mill, John Rawls, Amartya Sen, Iris Marion Young, Rodrigo Uprimny y Diana Esther Guzmán. ${ }^{9}$ A partir de allí, la justicia se define mediante diversos principios como el de la mayor felicidad, según Mill; igual libertad para todos e igualdad equitativa para todos, de acuerdo con Rawls; libertades fundamentales centradas en las capacidades de los individuos, para Sen; inclusión y política de la diferencia de los grupos oprimidos, según Young, y restitución plena o reparación integral y transformadora para Uprimny y Guzmán, lo cual permite concluir que es necesario apelar a las

9 Si bien la propuesta de Uprimny y Guzmán puede no ser vista necesariamente como una teoría de la justicia reconocida en el grueso trabajo de las teorías generales de la justicia, resulta muy útil traerla como una teoría particular que ayuda a dar desdoblar otro significado de la justicia en el campo de la especial protección. 
distintas acepciones de la justicia a partir de sus enfoques frente a cada grupo de especial protección.

\section{El problema ${ }^{10}$ de los sujetos y grupos desaventajados de especial protección en Colombia}

El estudio de los derechos humanos y fundamentales en Colombia plantea una preocupación prioritaria frente a aquellos individuos y grupos que, por razones diferenciadas con el resto de la población, son estigmatizados socialmente con un estatus de inferioridad que los hace desaventajados y vulnerables a la segregación, a la exclusión social, a la violación de sus prerrogativas y los priva injustamente de igualdad, libertad y solidaridad y, en general, de la posibilidad de gozar en idénticas condiciones de los mismos derechos de todos.

Tales razones injustificadas, sean estas de carácter natural (como la edad, el sexo, la raza, la etnia, las condiciones físicas o psicológicas) o de carácter social (como las condiciones económicas, el tipo de trabajo, el desempleo, la pobreza, el territorio, la pertenencia a un grupo social o político determinado, la diversidad, el orden público de una localidad, los hechos naturales irresistibles, la nacionalidad, la situación jurídica, la tradición), entre otras, son circunstancias que han determinado y determinan las posibilidades o grados de vida digna de los individuos en el contexto colombiano.

Paradójicamente, la identificación de esos factores ha servido para ir reconociendo progresivamente, a través del derecho colombiano, la idea de la diferencia y de las desventajas en que algunos se encuentran o que son socialmente colocados para hablar de especial protección en aquellos sujetos o grupos.

No obstante, ese modelo de reconocimiento jurídico ${ }^{11}$ ha generado en la doctrina un cuestionamiento al contenido y la capacidad de las normas y

10 El enfoque de la problemática se orienta a mostrar las dificultades que presenta la dogmática jurídico-estatal para la construcción y el funcionamiento del objeto jurídico de la especial protección; no obstante, este no se extiende a detallar los problemas específicos que padecen cada sujeto o grupo de especial protección, ya que cada uno por sí mismo podría constituir un objeto diferente de estudio.

$11 \mathrm{Al}$ respecto pueden citarse las posturas teóricas contemporáneas más influyentes en la materia que apelan por una teoría de reconocimiento más amplia de los sujetos y grupos desaventajados de especial protección: Axel Honneth (1992) defiende la idea de un reconocimiento recíproco o 
las instituciones legales, judiciales y administrativas para remediar materialmente ese estatus de inferioridad y desigualdad en que se les ha ubicado injustamente y ha mostrado la incapacidad del Estado y de la sociedad para avanzar hacia el desarrollo moral de los conflictos sociales relacionados con este fenómeno.

Esta situación ambivalente ha llevado a la pregunta por la existencia del objeto jurídico de la especial protección dentro del derecho colombiano o de su necesidad de construirlo a partir de los distintos discursos que aparecen en esta cuestión, entre ellos no solo el discurso tradicional del derecho, sino también otros discursos que vienen de los mismos sujetos y grupos de especial protección y de las organizaciones sin ánimo de lucro dedicados a la defensa de los derechos humanos; así como el discurso internacional que, en conjunto, constituyen la dogmática que hay detrás de este objeto.

A partir de lo anterior surgen otros interrogantes que dejan entrever las causas o variables de este problema sobre los cuales ni el derecho ni la cultura jurídica colombiana han dado una respuesta satisfactoria, esto es: ipuede afirmarse que el ordenamiento jurídico colombiano tiene un sistema jurídico de reconocimiento justo, integral y adecuado legislativo, administrativo y judicial que garantice materialmente la defensa reforzada de los llamados sujetos y grupos de especial protección, acorde con los distintos discursos que intervienen en la formación de este objeto jurídico?, o, por el contrario, ¿es necesario crear un modelo jurídico de reconocimiento justo, debidamente fundamentado, organizado y con una justicia apropiada para atender la demanda de dicha población?

\footnotetext{
intersubjetivo, resultado de un proceso, en el cual un sujeto adquiere la conciencia de sí mismo a partir de una segunda persona, interioriza e interactúa las normas sociales que resultan de la generalización de las expectativas de comportamiento de todos los miembros de la sociedad y pasa por un proceso de autoafirmación como una forma de defensa del propio yo frente al entorno social, que se da en el desplazamiento de la voluntad común hacia una comunidad de derecho ampliada. Nancy Fraser, por su parte, sostiene la tesis de que todo reconocimiento implica, también, una redistribución, y propone entender el reconocimiento desde un enfoque dual perspectivista, mediante el cual trata cada práctica social como económica y cultural al mismo tiempo, tanto el punto de vista de la distribución como del reconocimiento, sin reducir ninguna de estas perspectivas a la otra. Así, el reconocimiento es concebido como un tema de justicia que debe ser tratado como un asunto de estatus social y una cuestión de agencia política cuando se advierte a los sujetos de especial protección mismos (Fraser y Honneth, 2003). Finalmente, Roberto Gargarella (1999a y 1999b) y algunos profesores de la Universidad de Yale (Akhil Reed Amar, Drew Days, Owen Fiss, Peter Schuck, Reva B. Siegel, Robert A. Burt y Vichy Schultz) sostienen que el reconocimiento de los sujetos y grupos desaventajados es una cuestión urgente que tiene un objetivo valioso: introducir políticas preferenciales a su favor, con el fin de brindarles el debido trato que se les ha negado por la sociedad.
} 
Desde allí se cuestiona si la legislación existente sobre cada sujeto y grupo de especial protección con más de mil setecientas leyes ${ }^{12}$ ha promovido cambios importantes o es insuficiente para corregir las situaciones de desventaja en que se encuentran y contribuye a generar espacios de trato injusto según cada caso o qué cambios se hacen necesarios; así mismo, se interroga si las acciones del Estado han promovido cambios necesarios y suficientes para la igualación de sus derechos o qué acciones se requieren, y si teniendo en cuenta los casi dos mil casos ${ }^{13}$ sobre el particular, decididos por la Corte Constitucional colombiana a través de sentencias de tutela, constitucionalidad y unificación entre 1992 a 2013, se hace necesario construir un nuevo modelo de protección reforzada que tenga en cuenta las líneas jurisprudenciales en la materia y qué otros discursos por fuera del derecho estatal aparecen en el escenario de la construcción de este objeto jurídico. ${ }^{14}$

La búsqueda de una respuesta a estos interrogantes encuentra un vacío en la materia y advierte que en Colombia es necesario construir este objeto jurídico de la especial protección, ya que este se encuentra desdibujado en el lenguaje tradicional del derecho, encerrado en un discurso insuficiente, oscuro y desarticulado del Legislador, el Ejecutivo, los jueces y los demás discursos que vienen del contexto, aparte de que desconoce que esta problemática señala una dogmática más amplia y compleja edificada en conjunto con otros discursos sociales, políticos y económicos que, entre ellos, luchan por el poder de definición de inclusión o exclusión de los sujetos y grupos, sus circunstancias de especial protección y sus garantías.

En este orden de ideas, en Colombia no existe un sistema jurídico justo de defensa de los sujetos y grupos de especial protección de cara al trato justo que ellos esperan; hay una serie de instrumentos jurídicos que sumados no alcanzan a consolidar la idea del objeto jurídico de la especial protección.

12 Al respecto, como se ha mencionado, puede confrontarse esta información en: http:// www.lexbase.biz/normas/leyes/buscadorenleyes/niños,niñas,adolescentes,juventudes,adultomayo r,terceraedad,mujeres,madrescabezadefamilia,mujeresenestadodeembarazo,indigenas,gitanos,negri tudes,afrocolombianos,campesinos, discapacitados, invalidez,enfermos, mendigos, indigentes,damnifi cados,desplazados, desaparecidos,refugiados,extranjeros,especialprotección

13 Recuperado en: http://www.lexbase.biz/jurisprudencia/corteconstitucional/buscadorencorteconstitucional/sujetosdeespecialprotección

14 Como ejemplos pueden citarse los discursos de base de los mismos sujetos y grupos de especial protección, de las organizaciones sin ánimo de lucro defensoras de los derechos humanos nacionales e internacionales y de los organismos de derecho internacional. 
El estudio de este fenómeno permite sostener que el problema es de carácter histórico y sintomático pese a que dentro de esta categoría jurídica de especial protección encaja gran parte de los individuos ${ }^{15}$ y a que, constitucionalmente, desde 1991 se les ha reconocido expresamente en la Carta Fundamental del Estado. ${ }^{16}$

No obstante, es preciso señalar que ha sido a partir de la nueva Constitución Política que se vislumbra un mayor interés en la materia y avances en el desarrollo jurisprudencial del Texto Constitucional en la identificación de los sujetos, sus características y necesidades para la garantía de sus derechos humanos y fundamentales, así como ciertas acciones positivas del Estado, a pesar de los atrasos legislativos y también de las fallas administrativas.

También, en medio de este panorama se logra establecer una estructura no acabada de los sujetos y grupos identificados de especial protección a partir de cinco categorías: 1) En el grupo por sus circunstancias físicas, 1.1) en razón de la edad: los niños, niñas y adolescentes, juventudes, adulto

15 Quiere decir esto que la mayoría de los sujetos en Colombia sufre una circunstancia que merece especial protección del Estado, es decir, no se trata de una minoría de sujetos con situaciones desfavorables temporales; por el contrario, se trata de una mayoría con situaciones de desventaja que son históricas o permanentes y que no han recibido una respuesta satisfactoria a su demanda de especial protección. En este caso, es aplicable lo sostenido por Claudio Marcelo Kiper, al señalar que "hay grupos minoritarios que no necesitan protección porque aunque inferiores en número constituyen el elemento dominante dentro de la sociedad" (1998, pp. 57 y 58).

16 La apropiación y el uso habitual del término especial protección aparece con la nueva Constitución Política de Colombia de 1991 con la consagración nominativa y no taxativa de algunos sujetos y grupos de especial protección por parte del Estado. El artículo 13 superior señala expresamente: "El Estado promoverá las condiciones para que la igualdad sea real y efectiva y adoptará medidas a favor de grupos discriminados o marginados [...] protegerá especialmente a aquellas personas que por su condición económica, física o mental, se encuentren en circunstancia de debilidad manifiesta". Además de ello, se suman otros fundamentos como: el preámbulo, los artículos 1 (fundamento del Estado Social de Derecho), 2 (fines esenciales del Estado), 13 (fundamento general de todos los sujetos de protección reforzada), 42 (hijos nacidos fuera del matrimonio), 43 (referido a las mujeres, al que está por nacer, a la mujer en embarazo y a la mujer cabeza de familia), 44 (protector de los niños y niñas), 45 (defensor de los adolescentes), 46 (referido a las personas de la tercera edad), 47 (protector de los disminuidos físicos, sensoriales y síquicos), 49 (referido a la salud de las personas y a los enfermos), 50 (protege a todo niño menor de un año), 51 (referido al trabajador, a la mujer, a la maternidad y al trabajador menor de edad, los minusválidos), 65 (defensor del productor de alimentos), 73 (protector especial del periodista), 85 (derechos de aplicación inmediata) y 86 (acción de tutela, instrumento de protección de los sujetos de especial protección). Contrario a este régimen constitucional, la Constitución de 1886 fue más escueta al respecto, solo hacía referencia al caso de los extranjeros, de quien la ley se encargaría de regular los derechos especiales, y de los esclavos que pisaran territorio colombiano, quienes quedaban libres. En lo demás, la Corte Suprema de Justicia reconoció la inconstitucionalidad de algunas normas que trataban injustamente a algunos sujetos de la sociedad; sin embargo, el problema no mereció la relevancia que ha mostrado bajo el nuevo régimen constitucional, ni los desarrollos constitucionales que se han presentado en estos tiempos. 
mayor y tercera edad; 1.2) en virtud de alguna limitación fisica: las personas con una discapacidad física o capacidades diferentes. 2) En el grupo por sus condiciones psicológicas: las personas con alguna limitación mental o capacidades diferentes. 3) En el grupo de las víctimas de violencia generalizada: los desplazados, torturados, secuestrados, desaparecidos, refugiados, exiliados, líderes políticos y miembros de partidos políticos, periodistas y habitantes en zonas con problemas de orden público; 4) en el grupo de los sujetos tradicionalmente discriminados, por el sexo: las mujeres, madres cabeza de familia, mujeres en estado de embarazo; por la etnia o raza: indígenas, gitanos, negritudes, afrocolombianos, raizales, palenqueros; por el lenguaje: las minorías lingüísticas; por orientación sexual: los LGTBIQ; por la nacionalidad: extranjeros, inmigrantes y migrantes colombianos; por el estado de salud: los que padecen una enfermedad grave, incurable o ruinosa y los incapacitados; por la orientación religiosa: las minorías religiosas, por la situación jurídica: las personas privadas de la libertad; por la calidad de trabajador: según el tipo de empleo. Y 5) en el grupo de los sujetos en condiciones de pobreza, inferioridad, subordinación, dependencia, marginalidad, territorio y precariedad económicas están los pobres, consumidores, trabajadores, desempleados, campesinos, mendigos, habitantes de calle y los damnificados.

Una lectura de este mapa inacabado permite visualizar la complejidad del problema, empezando por la diversidad de los sujetos dentro de dichos grupos, sus variadas circunstancias, la posibilidad de que un sujeto pertenezca a varios de estos grupos o a todos, la necesidad de una debida intervención del Estado a través del Legislador, el Ejecutivo y los jueces y la ausencia de estrategias adecuadas que promuevan cambios positivos orientados a la materialización de la igualdad, la libertad y la solidaridad social, según las necesidades de cada caso.

Ahora bien, tratar de descifrar más a fondo este problema, implica ahondar en las fallas que ha tenido el discurso tradicional del derecho colombiano en el tratamiento de la situación de los mencionados sujetos y grupos, quienes más que un remedio se han encontrado con los límites que tiene el derecho para la realización de sus derechos humanos y fundamentales y su protección especial.

En el plano del discurso legislativo, existe un marco regulatorio incompleto, disperso y complejo que lleva hacia un desconocimiento generalizado 
de la población sobre la dotación de sus derechos especiales, deberes, garantías y acciones.

Este discurso legal ${ }^{17}$ hace parte de una serie gradual de mandatos formales ${ }^{18}$ mediante los cuales el legislador históricamente se ha pronunciado so-

17 De acuerdo con la base de datos LexBase, no existe regulación legal específica sobre sujetos o grupos de especial protección en Colombia o sobre circunstancias de especial protección; por lo tanto, se hizo necesario hacer una búsqueda sin límite temporal a partir de cada uno de los ya identificados como sujetos de especial protección. Así, se halló cuantitativamente que en la legislación hay sobre niños, niñas y adolescentes (178 leyes), juventudes (91 leyes), adulto mayor (21 leyes), tercera edad (46 leyes), mujeres ( 141 leyes), madres cabeza de familia (29 leyes), mujeres en estado de embarazo (50 leyes), indígenas ( 12 leyes), gitanos ( 7 leyes), negritudes ( 15 leyes), afrocolombianos (7 leyes), campesinos (64 leyes), LGTBI (no se encuentra por este término, por diversidad hay 108 leyes), discapacitados (11 leyes), disminuido (42 leyes), invalidez (137 leyes), los que padecen de una enfermedad grave o ruinosa (67 leyes), mendigos ( 14 leyes), indigentes ( 23 leyes), habitantes de calle (no hay), damnificados (49 leyes), desplazados (51 leyes), torturados, secuestrados o desaparecidos (116 leyes), refugiados (31 leyes), exiliados, líderes políticos, presos, extranjeros (413 leyes), inmigrantes (20 leyes).

18 Entre la extensa legislación se citan algunas de las leyes expedidas entre 1990 y 2014 : Tercera edad: 50 (1990), 105 (1993), 160 (1994), 223 (1995), 333 (1996), 400 (1997), 490 (1998), 508 (1999), 599 (2000), 629 (2001), 789 (2002), 820 (2003), 915 (2004), 1101 (2006), 1151 (2007), 1251 (2008), 1341 (2009), 1417 (2010), 1482 (2011), 1593 (2012), 1617 (2013). Campesinos: 4 (1990), 14 (1991), 104 (1993), 161 (1994), 223 (1995), 333 (1996), 418 (1997), 534 (1999), 611 (2000), 789 (2002), 812 (2003), 1152 (2007), 1448 (2011), 1564 (2012), 1622 (2013). Damnificados: 45 (1990), 104 (1993), 241 (1995), 340 (1996), 418 (1997), 782 (2002), 1066 (2006), 1152 (2007), 1430 (2010), 1488 (2011), 1523 (2012). Desaparecidos: 45 (1990), 11 (1992), 81 (1993), 137 (1994), 222 (1995), 356 (1997), 406 (1997), 472 (1998), 522 (1999), 609 (2000), 721 (2001), 733 (2002), 769 (2002), 836 (2003), 877 (2004), 991 (2005), 1121 (2006), 1142 (2007), 1268 (2008), 1336 (2009), 1426 (2010), 1478 (2011), 1592 (2012), 1675 (2013). Desplazados: 111 (1994), 188 (1995), 265 (1996), 368 (1997), 443 (1998), 508 (1999), 590 (2000), 715 (2001), 785 (2002), 833 (2003), 909 (2004), 975 (2005), 1112 (2006), 1152 (2007), 1268 (2008), 1304 (2009), 1380 (2010), 1450 (2011). Diversidad-diversidad sexual-LGBTI: 21 (1991), (1992), 99 (1993), 165 (1994), 218 (1995), 304 (1996), 411 (1997), 464 (1998), 536 (1999), 600 (2000), 715 (2001), 768 (2002), 850 (2003), 906 (2004), 1000 (2005), 1109 (2006), 1166 (2007), 1268 (2008), 1360 (2009), 1412 (2010), 1493 (2011), 1601 (2012), 1670 (2013). Enfermos: 56 (1990), 17 (1991), 100 (1993), 171 (1994), 320 (1996), 380 (1997), 522 (1999), 599 (2000), 715 (2001), 767 (2002), 916 (2004), 949 (2005), 1164 (2007), 1268 (2008), 1414 (2010), 1435 (2011), 1517 (2012), 1616 (2013). Extranjeros: 49 (1990), 17 (1991), 31 (1992), 106 (1993), 172 (1994), 251 (1995), 340 (1996), 412 (1997), 488 (1998), 526 (1999), 633 (2000), 703 (2001), 788 (2002), 864 (2003), 938 (2004), 996 (2005), 1121 (2006), 1180 (2007), 1232 (2008), 1349 (2009), 1430 (2010), 1493 (2011), 1607 (2012), 1673 (2013). Gitanos: 812 (2003), 1151 (2007), 1189 (2008), 1342 (2009), 1381 (2010), 1450 (2011), 1530 (2012). Indígenas: 21 (1991), 145 (1994), 188 (1995), 482 (1998), 992 (2005), 1020 (2006), 1151 (2007). Invalidez, disminuido-discapacitado: 49 (1990), 27 (1992), 106 (1993), 174 (1994), 241 (1995), 345 (1996), 418 (1997), 490 (1998), 549 (1999), 608 (2000), 715 (2001), 789 (2002), 863 (2003), 938 (2004), 1000 (2005), 1112 (2006), 1170 (2007), 1268 (2008), 1371 (2009), 1430 (2010), 1448 (2011), 1607 (2012). Juventud: 18 (1991), 65 (1993), 150 (1994), 237 (1995), 344 (1996), 397 (1997), 482 (1998), 547 (1999), 624 (2000), 768 (2002), 862 (2003), 978 (2005), 1098 (2006), 1151 (2007), 1189 (2008), 1336 (2009), 1475 (2011), 1599 (2012), 1622 (2013). Mujeres: 21 (1991), 5 (1992), 82 (1993), 171 (1994), 248 (1995), 333 (1996), 387 (1997), 488 (1998), 516 (1999), 590 (2000), 691 (2001), 789 (2002), 860 (2003), 923 (2004), 994 (2005), 1109 (2006), 1152 (2007), 1268 (2008), 1670 (2013). Madre-cabeza de 
bre cada uno de los sujetos y grupos mencionados, sin que pueda concluirse que hay claridad, precisión e identidad sobre las especiales circunstancias en que aquellos deben protegerse, esto debido a que el legislador ha omitido establecer de manera clara un marco jurídico en el cual se defina quiénes son los sujetos y grupos de especial protección, cuáles son sus especiales circunstancias que los hace merecedores a una mayor protección y cuáles son las acciones o medidas adoptadas para erradicar sus situaciones de desventaja con respecto a los demás ciudadanos colombianos.

Esta especie de normatividad, por lo general, se compone de normas amplias o abiertas, sin presupuesto propio y como una carga más de las funciones que debe cumplir un órgano del Estado o una entidad territorial. Son leyes dispersas, asistémicas y simbólicas que tratan de manera tangencial y por separado los diversos sujetos, sin que necesariamente por su contenido se estipule una especial protección.

En vista de lo anterior, el legislador se ha mostrado incapaz técnicamente de producir un conjunto normativo claro, expreso y exigible para la pluralidad de los sujetos y grupos de especial protección según sus especiales circunstancias.

Frente a esta situación de omisión legislativa o de legislación imperfecta es patente que el ciudadano colombiano desconozca quiénes son los sujetos y grupos de especial protección dentro del ordenamiento jurídico; cuándo se ostenta esta calidad; qué requisitos convergen en cada caso; las normas que los rige; los principios, derechos, deberes, obligaciones, garantías y prestaciones que tienen y el tratamiento diferenciado entre ellos; las acciones

familia: 3 (1991), 82 (1993), 136 (1994), 333 (1996), 387 (1997), 508 (1999), 790 (2002), 861 (2003), 906 (2004), 1152 (2007), 1232 (2008), 1429 (2010), 1469 (2011), 1551 (2012), 1632 (2013). Mujer en estado de embarazo-embarazo: 50 (1990), 65 (1993), 248 (1995), 320 (1996), 347 (1997), 443 (1998), 516 (1999), 599 (2000), 742 (2002), 841 (2003), 909 (2004), 984 (2005), 1098 (2006), 1151 (2007), 1268 (2008), 1350 (2009), 1418 (2010), 1468 (2011), 1564 (2012), 1622 (2013). Mendicidad: 4 (1991), 100 (1993), 136 (1994), 188 (1995), 344 (1996), 413 (1997), 482 (1998), 547 (1999), 599 (2000), 714 (2001), 780 (2002), 848 (2003), 985 (2005), 1098 (2006), 1276 (2009), 1588 (2012). Negritudes: 70 (1993), 218 (1995), 261 (1996), 359 (1997), 463 (1998), 508 (1999), 722 ( 2001), 1000 (2005), 1042 ( 2006), 1152 (2007), 1251 (2008), 1669 (2013). Niños, niñas y adolescentes: 18 (1990), 21 (1991), 11 (1992), 100 (1993), 173 (1994), 248 (1995), 335 (1996), 418 (1997), 469 (1998), 515 (1999), 633 (2000), 724 (2001), 789 (2002), 833 (2003), 906 (2004), 994 (2005), 1109 (2006), 1171 (2007), 1268 (2008), 1359 (2009), 1421 (2010), 1503 (2011), 1607 (2012), 1670 (2013). Refugiados: 33 (1990), 12 (1991), 11 (1992), 137 (1994), 320 (1996), 469 (1998), 525 (1999), 800 (2003), 898 (2004), 1108 (2006), 1349 (2009), 1407 (2010), 1604 (2012). Víctimas: 11 (1992), 104 (1993), 188 (1995), 418 (1997), 986 (2005), 1098 (2006), 1448 (2011), 1596 (2012). 
y los procedimientos que se deben seguir; las autoridades encargadas; los términos con que cuentan; las prelaciones prestacionales; las conductas prohibidas; los controles, y las sanciones aplicables.

Esto desemboca en una normatividad inerte, en la insatisfacción de los derechos y necesidades de los mencionados sujetos; en una indebida orientación legal de los recursos públicos y un medio de huida ilegal de estos; en una equivocada, desestructurada e insuficiente política legislativa; en un inequitativo tratamiento entre los sujetos que ostentan la calidad de especial protección, y en una fuente de inseguridad jurídica y de generación de injusticia social. El resultado, finalmente, es la ausencia de una solución legislativa justa, integral, armónica y estratégica que impacte favorablemente los sujetos, el funcionamiento del Estado y su desarrollo.

En cuanto al discurso administrativo, la función regulatoria la ha asumido el Ejecutivo en el ámbito nacional ${ }^{19} \mathrm{y}$ en sus distintos entes territoriales, y a partir de allí, estratégicamente, según el gobierno de turno, la rama Ejecutiva juega a fortalecerse, a través de una política pública de promesas que, en la mayoría de los casos, no logra cumplir a cabalidad en la realidad.

Vale señalar que el tratamiento mediático de los gobiernos de turno frente a algunos sujetos y el olvido de otros o la categorización entre ellos y las oportunidades que se dan para unos y otros, así como la particular disposición y ejecución presupuestal frente cada grupo de especial protección, hace que haya un escenario de inseguridad y desconfianza para el logro de una política administrativa justa y permanente que garantice de manera adecuada la situación de estos sujetos.

Lo anterior está viciado de la falta de técnica regulativa heredada del legislador y trae consigo un amplio margen de discrecionalidad de la administración pública para atender una problemática que no ha sido bien

19 Una muestra de ese discurso se halla en los decretos expedidos por el Gobierno nacional, en ese mismo periodo entre 1990 y 2014, entre ellos se encuentran: 775 (1990), 1843 (1991), 36 (1992), 37 (1992), 1088 (1993), 2381 (1993), 924 (1994), 1279 (1994), 82 (1996), 3115 (1997), 24 (1998), 636 (1998), 2647 (1999), 1729 (2002), 3210 (2002), 3232 (2002), 50 (2003), 1747 (2003), 3770 (2003), 4003 (2004), 4360 (2004), 250 (2005), 4686 (2005), 3391 (2006), 4580 (2006), 3600 (2007), 4965 (2007), 3905 (2008), 1997 (2009), 4550 (2009), 4735 (2009), 126 (2010), 433 (2010), 1740 (2010), 2957 (2010), 4803 (2010), 4817 (2010), 1490 (2011), 4065 (2011), 4100 (2011), 4629 (2011), 4633 (2011), 4634 (2011), 4635 (2011), 4800 (2011), 4801 (2011), 4944 (2011), 445 (2012), 2715 (2012), 34 (2013), 48 (2013), 211 (2013), 442 (2013), 722 (2013), 1987 (2013), 1988 (2013), 2210 (2013), 2766 (2013), 2852 (2013), 3036 (2013), 20 (2014), 25 (2014), 64 (2014), 901 (2014). 
definida en la ley, en virtud de lo cual el Ejecutivo ha aprovechado para adoptar medidas mediáticas y de conveniencia del gobierno de turno a través de la implementación de una regulación administrativa mínima, dispersa, cambiante y conforme con la agenda de cada ente territorial, que en la mayoría de las veces resulta insuficiente a las necesidades que demandan dichos sujetos y grupos.

Esto va aparejado a la ausencia de un marco general reglamentario de la especial protección nacional y, en consecuencia, a un vacío dentro del modelo regulativo del Ejecutivo, que demuestra una falta de capacidad del Estado para dar una reglamentación general que defina de manera integral su papel nacional y descentralizado para todos los sujetos y grupos de protección especial.

Además de lo anterior, la administración pública, en sus diferentes estamentos, se enfrenta a graves dificultades que impiden un tratamiento adecuado a esta población; esto es, la politización perversa de la función administrativa, la falta de equipo de trabajo especializado, la burocratización de los cargos públicos, la promoción de la cultura de la mendicidad de los derechos, la ausencia de representación y participación de los sujetos y grupos de especial protección, la exclusión, los cambios de políticas según el gobierno de turno, la diversidad e inequidad de políticas entre los distintos entes territoriales, la concentración de la administración en lo urbano y el olvido de lo rural, la carencia de recursos suficientes y necesarios para la inversión social, la falta de un lenguaje común entre los sujetos de especial protección y la administración y la imposibilidad de aquellos para demandar efectivamente la acción del Estado y el gasto público.

Así mismo, se enfrenta a una normatividad sobre políticas públicas con problemas de organización, sistematicidad, coherencia, publicidad, generalidad, exigibilidad, socialización y adecuada distribución de los recursos públicos. De esta forma, el papel del Ejecutivo en sus distintos ámbitos tampoco ha gestado una apuesta por la implementación de un derecho justo para la problemática de los sujetos y grupos de especial protección; por el contrario, ha contribuido con su agudización y su propia deslegitimación ante la incapacidad administrativa para satisfacer sus necesidades. ${ }^{20}$

20 Esto se puede evidenciar de manera general en las estadísticas del último censo nacional de 2005 realizado por el Departamento Administrativo Nacional de Estadística, en el cual se puede 
Respecto al discurso judicial, ha sido el juez constitucional, especialmente la Corte Constitucional, ${ }^{21}$ el que ha dado luces en relación con la definición de la categoría jurídica de los sujetos de especial protección y sus distintos tipos y ha colocado en evidencia la omisión legislativa en el tema, así como la constante violación de las entidades y organismos del Estado hacia los derechos humanos y fundamentales de estos sujetos. ${ }^{22}$

La Corte comenzó a hablar del tema cuando evidenció que era necesario responder con justicia frente a unos sujetos que denominó de trato

reconocer la magnitud de la problemática frente al aumento frecuente de la población de especial protección sin que el Estado logre cambiar esa realidad con sus normas o con sus acciones. Véase: https://www.dane.gov.co/index.php/poblacion-y-registros-vitales/censos/censo-2005

${ }^{21}$ La Corte Constitucional colombiana, como máximo órgano de la jurisdicción constitucional, encargada de la guarda, la integridad y la supremacía de la Constitución Nacional, ha actuado en materia de especial protección, a partir de su función de la eventual revisión de las sentencias de tutela, de su función de control constitucional por medio de las sentencias de constitucionalidad y mediante su función de unificación de su jurisprudencia y de máxima intérprete constitucional mediante las sentencias de unificación que operan como precedentes judiciales vinculantes para los demás funcionarios y órganos jurisdiccionales.

22 Todo ello es visto claramente en las 1916 sentencias proferidas por este máximo órgano constitucional entre 1992 y 2014, de las cuales cito algunos ejemplos reveladores que sirven para mostrar cómo la Corte Constitucional, año a año, ha ido definiendo el núcleo esencial del derecho a la especial protección, en general, y ha desarrollado una jurisprudencia respecto de cada sujeto que ha denominado de especial protección, en particular. Entre estas destaco las sentencias de unificación: SU-388 (2005), SU-62 (2010), SU-446 (2011), SU-897 (2012), SU-1073 (2012), SU-70 (2013), SU-132 (2013), SU-254 (2013); las sentencias de Constitucionalidad: C-185 (1999), C-891 (2002), C-991 (2004), C-54 (2005), C-59 (2005), C-113 (2005), C-180 (2005), C-203 (2005) C-381 (2005), C-534 (2005), C-674 (2005), C-707 (2005), C-1192 (2005), C-1262 (2005), C-355 (2006), C-664 (2006), C-716 (2006), C-862 (2006), C-989 (2006), C-78 (2007), C-278 (2007), C-294 (2007), C-338 (2007), C-342 (2007), C-491 (2007), C-653 (2007), C-720 (2007), C-932 (2007), C-951 (2007), C-1000 (2007), C-1003 (2007), C-1041 (2007), C-34 (2008), C-318 (2008), C-463 (2008), C-507 (2008), C-540 (2008), C-740 (2008), C-838 (2008), C-842 (2008), C-857 (2008), C-862 (2008), C-864 (2008), C-901 (2008), C-904 (2008), C-1065 (2008), C-1186 (2008), C-1198 (2008), C-149 (2009), C-240 (2009), C-289 (2009), C-372 (2009), C-406 (2009), C-428 (2009), C-442 (2009), C-443 (2009), C-444 (2009), C-468 (2009), C-640 (2009), C-662 (2009), C-663 (2009), C-684 (2009), C-727 (2009), C-793 (2009), C-795 (2009), C-850 (2009), C-853 (2009), C-892 (2009), C-14 (2010), C-55 (2010), C-145 (2010), C-173 (2010), C-184 (2010), C-252 (2010), C-288 (2010), C-302 (2010), C-317 (2010), C-775 (2010), C-776 (2010), C-830 (2010), C-840 (2010), C-029 (2011), C-221 (2011), C-300 (2011), C-397 (2011), C-398 (2011), C-438 (2011), C-539 (2011), C-577 (2011), C-620 (2011), C-629 (2011), C-748 (2011), C-791 (2011), C-824 (2011), C-876 (2011), C-900 (2011), C-936 (2011), C-027 (2012), C-122 (2012), C-255 (2012), C-296 (2012), C-331 (2012), C-383 (2012), C-540 (2012), C-605 (2012), C-606 (2012), C-609 (2012), C-640 (2012), C-644 (2012), C-710 (2012), C-715 (2012), C-718 (2012), C-744 (2012), C-783 (2012), C-847 (2012), C-910 (2012), C-011 (2013), C-54 (2013), C-66 (2013), C-258 (2013), C-330 (2013), y entre las sentencias de tutela: T-006 (1992), T-008 (1992), T-414 (1994), T-116 (1995), T-347 (1996), T-393 (1997), T-618 (1998), T-412 (1999), T-1531 (2000), T-1320 (2001), T-1084 (2002), T-1191 (2003), T-1236 (2004), T-1331 (2005), T-1080 (2006), T-1097 (2007), T-1264 (2008), T-973 (2009), T-1059 (2010), T-981 (2011), T-1095 (2012), T-362 (2013), T-043 (2014). 
diferencial positivo. Esto puede verse desde sus primeros pronunciamientos en las sentencias T-006 de 1992 y T-008 de 1992, en las cuales empieza a referirse a los derechos asistenciales de tratamiento prioritario y preferente, frente a los cuales sostuvo y mantiene la idea de que en la especial protección:

[...] aplica la filosofía esencial del Estado Social de Derecho, que se traduce en el deber de proteger a las personas que por su condición económica, física o mental, se encuentren en circunstancias de debilidad manifiesta, para hacer que la igualdad sea real y efectiva; por ello no resultaría eficaz el principio de igualdad, si todas las personas fueran tratadas de la misma manera, es decir, sin tener en cuenta las particulares circunstancias en que cada una se encuentra (Corte Constitucional, T-347 de 1996).

Desde allí ha dirigido este problema atendiendo caso por caso, sentando posiciones y líneas jurisprudenciales respecto de cada sujeto, tal y como ya se ha mencionado en otros puntos de este texto, al punto que se registran 1916 pronunciamientos de tutela, constitucionalidad y sentencias de unificación entre 1992 a 2013 en los cuales le ha correspondido decidir sobre algún sujeto o grupo de especial protección.

Dicha cifra es significativa, considerando que la jurisprudencia de la Corte solo conoce de algunos casos y que la gran mayoría de estos se quedan, en materia de tutela, en instancias inferiores. Esto demuestra que en Colombia no hay una materialización de la especial protección y que los sujetos que entran en esta categoría, por lo general, se ven obligados a acudir a la jurisdicción constitucional para exigir su protección reforzada.

Lo anterior muestra una desconexión entre lo preceptuado constitucionalmente y lo que, a partir de allí, se ha esperado por más de veinte años, en la tarea de dar una respuesta legislativa y administrativa justa, eficiente y eficaz a los sujetos y grupos de especial protección, donde la excepción sea que estos tengan que acudir a la vía judicial para que se les reconozca lo que por derecho se les ha conferido constitucionalmente.

A todas luces, si bien la labor de la Corte ha sido fundamental, esta no deja de ser una vía excepcional, mediática, judicial y particular que no es la llamada en primer lugar para tratar y garantizar la especial protección y darle una solución de fondo a la problemática. Vale decir, el juez no tiene, en principio, unas formas adecuadas para garantizar siempre de manera 
clara, eficiente, organizada, pública, sistemática y autónoma, a través de sus decisiones judiciales, los derechos especiales de esta población.

Lo anterior, en razón a que la jurisprudencia de los jueces adolece de superproducción, dispersión o desorganización y a que la mayoría de veces es aplicable solo al caso concreto; además, tiene problemas de exigibilidad, es variable, se ve enfrentada a las luchas entre las altas cortes, tiene un lenguaje técnico y difícil de entender y apropiar por los sujetos y grupos de especial protección y, además, se cuestiona que con ella se coloca en juego la democracia.

Al mismo tiempo, porque estos sujetos no cuentan con una vía judicial principal para demandar la especial protección, ni con un procedimiento o una acción especial para estos asuntos, y allí también los jueces se ven impedidos para atender cualquier demanda sobre el particular. Es decir, la materia está supeditada a la acción subsidiaria de la tutela que conforme con la doctrina de la Corte Constitucional del amparo reforzado de los sujetos (Corte Constitucional colombiana, T-736 de 2013) ha aceptado su uso en ciertos casos y ha ido avanzado en el reconocimiento progresivo pero restringido del reconocimiento de las circunstancias y los sujetos y grupos que considera de especial protección (Cortés, 2007, pp. 130-134).

Por lo tanto, esta vía de los jueces y sus normas providenciales también hacen parte del problema que poseen estos sujetos para la defensa de sus circunstancias de especial protección; en tanto que las acciones ejercidas en su tutela son residuales, particulares, litigiosas, costosas, del arbitrio judicial, generan desgaste del ciudadano y los jueces y una excesiva concentración del poder en las altas cortes.

Ahora bien, aquí también se cuestiona la ausencia del legislador en la materia, pues a partir de allí la labor de los jueces y las altas cortes también ha sido limitada y parcial a la magnitud del problema que tiene el país para dar una respuesta jurídica a estos sujetos; su valioso aporte ha sido tratar de crear y aplicar su jurisprudencia frente a quienes han llegado a considerar de especial protección, pero esta función no garantiza, entre otras razones, por falta de competencia, un marco regulatorio adecuado y exigible para todos estos sujetos y grupos.

Lo anterior ha significado un cuestionamiento al tratamiento que han recibido los sujetos de especial protección por parte del ordenamiento jurídico pues, a toda vista, ante un Estado Social y Democrático de derecho, 
este ha sido débil para los ciudadanos que tienen que dar primero las batallas judiciales para discutir sus derechos y esperar un pronunciamiento sabio del juez que en efecto lo reconozca y le brinde su protección.

Este escenario plantea un problema de múltiples injusticias sociales puntualizadas en situaciones particulares de desprotección de cada uno de los sujetos y grupos de especial protección que no encuentran en el derecho una fuente generadora de justicia o, como lo expresa, por otro lado, en sentido más amplio, el exmagistrado Eduardo Cifuentes Muñoz (2014), cuando afirma que esto nos muestra que la sociedad no está a la altura de la indicada medida de respeto a la dignidad humana y de respuesta solidaria que se plasma en la Constitución, lo cual constituye un déficit en el respeto y trato adecuado de los sujetos.

Así mismo, es necesario reconocer que el problema de la dogmática de la especial protección no gira solo en torno del discurso legislativo, administrativo y judicial nacional; es decir, parte importante del problema tiene que ver con el desconocimiento injusto de otros discursos que no siempre son aceptados en el discurso del derecho formal, pero que participan en la construcción de este objeto jurídico.

Esto es, en la problemática, ese discurso formal imperante del derecho se ve confrontado por el discurso de derecho ampliado de los mismos sujetos y grupos de especial protección; las organizaciones sin ánimo de lucro, la comisión de juristas, las organizaciones para la defensa de los derechos humanos, las organizaciones e instituciones internacionales, la Comisión de los Derechos Humanos y las cortes internacionales, que han participado con sus prácticas discursivas en la lucha por el contenido y las formas de la especial protección que, en últimas, resultan sometidas al discurso asimétrico del derecho estatal que se impone a través del ejercicio de las relaciones de poder y de fuerza que se dan entre los discursos estatales y no estatales, como acertadamente lo señaló Michael Foucault (Hunt y Wickham, 1994).

Ahora bien, la identificación de estas causas y variables del problema de los sujetos y grupos de especial protección en Colombia implica ir más allá, conlleva plantear una tesis, que para nada es pacífica, según la cual existe una conexión íntima con un problema más de fondo de orden teórico respecto de los derechos especiales, que incide de manera determinante en su materialización; esto es, el derecho colombiano está edificado en teorías tradicionales dominantes de corte positivista (López, 2008) que excluyen o 
aceptan de modo contingente pero no necesario la relación entre el derecho y la justicia, lo que ha permitido a través del derecho formal y práctico mantener el statu quo de dichos sujetos y la justificación del derecho estatal para no responder a sus demandas de justicia.

Lo anterior permite afirmar que en Colombia hay una indebida concepción teórica del derecho y, por tanto, una ausencia de fundamentación teórica adecuada que reconozca de forma necesaria esa relación entre el derecho y la justicia, a partir de lo cual se pueda sustentar una dogmática integral de estos derechos de especial protección y concebir este objeto jurídico desde un diálogo mediado por el derecho y la justicia con los demás discursos no estatales propios de la base social.

Por esta razón se pasa a abordar esta cuestión en los títulos siguientes y se deja en claro que una teoría de los derechos especiales de los sujetos y grupos desaventajados no es ajena a la discusión teórica que existe en el medio de dos extremos, por un lado, el de la teoría del derecho y, por el otro, el de las teorías de la justicia.

\section{El problema de la inexistencia de una teoría adecuada del derecho de base para los derechos especiales de los sujetos y grupos desaventajados a partir de la relación necesaria entre el derecho y la justicia}

El problema bajo estudio tiene como punto de partida una discusión teórica conceptual y normativa de largo aliento asociada con la compleja relación entre el derecho y la justicia, que se evidencia en la confrontación de las distintas teorías del derecho y de la justicia más influyentes en la actualidad, en medio de lo cual la tesis de los sujetos y grupos desaventajados apela por defender dos presupuestos básicos: el primero es la existencia de un vínculo entre el derecho y la justicia y el segundo, como consecuencia del anterior, es la necesidad de adoptar en lo jurídico las teorías de la justicia para comprender, interpretar y determinar el derecho de los sujetos y grupos de especial protección.

Dichos presupuestos surgen, a su vez, de un interrogante subyacente en la investigación, que es la pregunta por el derecho "justo" para los sujetos y grupos de especial protección. Ello nos lleva a revisar 1) la naturaleza del 
derecho, si este es justo, o mejor, si existe una relación necesaria entre el derecho y la justicia, cuya respuesta deviene de la discusión teórica sobre qué es el derecho, y 2) qué es lo justo para los sujetos y grupos de especial protección.

Este título aborda la primera cuestión, es decir, la pregunta obligada de la teoría del derecho sobre la vinculatoriedad o no de la justicia al concepto del derecho y se argumenta la tesis, según la cual toda teoría del derecho que pretenda aproximarse al concepto del derecho en un Estado moderno debe incluir la justicia como uno de sus elementos conceptuales necesarios que le proporciona la mejor explicación de los rasgos del derecho, pues se expresa como su fundamento moral y, a la vez, como su argumento funcional, en cuanto contenido mínimo y criterio interpretativo de corrección del sistema jurídico a través del cual se pretende alcanzar el sentido correcto del derecho.

El desarrollo de esta tesis entra en esa discusión de la relación necesaria entre el derecho y la justicia, en búsqueda de una teoría base de los derechos especiales de los sujetos y grupos de especial protección, y parte de la confrontación teórica entre los teóricos del derecho más influyentes en la modernidad; pasando por diferentes posturas: la exclusión, la inclusión contingente y la inclusión necesaria, posición última que sustenta la tesis de la investigación y que abre la necesidad de entender el derecho y la justicia como conceptos interpretativos conceptual y funcionalmente ligados.

\subsection{Sujetos y grupos de especial protección por fuera del derecho: desde una concepción del derecho desligada de la justicia}

Esta noción teórica vista en Kelsen (1934), Austin, Hart (1941), Atria (2004) y Raz (2007), en mayor o menor grado, rechaza la vinculación necesaria entre el derecho y la justicia, en razón de lo cual el problema de los sujetos y grupos desaventajados no forma parte de las cuestiones obligadas a las cuales tiene que dar respuesta el derecho. Postura equivocada que ha generado confusiones en el entendimiento de lo qué es el derecho y sus funciones dentro de los distintos ordenamientos jurídicos.

Un ejemplo de ellos es avizorado en Hart en su obra El concepto del derecho, que inicia destacando esta cuestión y planteando las preguntas persistentes, los problemas recurrentes y las dificultades para construir una definición 
del concepto del derecho en la teoría jurídica. Sostiene que entre estos problemas se encuentra la distinción entre el concepto del derecho y la moral, en medio de lo cual la idea de la justicia, más que ayudar a distinguir ambos campos, sirve para confundirlos ya que, a partir de allí, se empieza a hablar de la "justicia de acuerdo con el derecho", y también de la justicia o la injusticia de las normas del derecho (Hart, 1941, pp. 1-9). Por consiguiente, afirma que: "estos hechos sugieren el punto de vista de que el derecho es entendido mejor como una rama de la moral o de la justicia y que es su congruencia con los principios de moral o justicia y no el hecho de que constituye un cuerpo de órdenes y amenazas lo que hace su 'esencia" (Hart, 1941, pp. 9 y 10).

Al respecto, él encuentra esto equivocado y propio de las teorías del derecho natural y de cierta teoría jurídica contemporánea que crítica el positivismo jurídico, y va aún más allá: sostiene que "la afirmación de que 'una norma jurídica injusta no es una norma jurídica', [no] suena tanto a exageración y a paradoja, sino a falsedad" (Hart, 1941, pp. 9 y 10).

Tan categórica es su aseveración que termina considerando como su principal antagonista aquellas teorías que tienen la pretensión rival de que se entiende mejor el derecho a través de su conexión con la moral y que, en todo caso, prefiere la teoría simple de Austin con sus errores que concibe el derecho como "órdenes respaldadas por amenazas" (Hart, 1941, p. 20).

En este sentido, aunque a Hart se le ha considerado un positivista suave o incluyente por importantes teóricos, las posturas descritas no permiten concluir tajantemente tal premisa, ya que también existen argumentos para sostener que Hart fue más bien contradictorio en este punto y no pretendió establecer una relación necesaria entre derecho y justicia; por lo cual su legado fue precisamente separar estas cuestiones que consideró problemáticas, buscar una mejor comprensión de lo que para él era el derecho desligado de la moral y la coerción y adoptar, por otro lado, la idea de regla para proponer un concepto del derecho a partir de un sistema jurídico estructurado en reglas.

Así, en algunos apartes de su teoría, el autor deja de lado la preocupación por el derecho justo y centra su interés en el derecho reglado, como unión de reglas primarias y secundarias sin que en ningún caso se le atribuya al contenido de dichas reglas una condición interna, necesaria y funcional de la justicia. Ello parece sostener que el contenido de las reglas definitorias 
del derecho puede ser cualquiera, sea este justo e injusto (Hart, 1941, pp. 102-120), lo que definitivamente no puede ser. El derecho en ningún caso puede ser injusto ni tender a la injusticia, porque deja de tener uno de sus rasgos característicos

Por tanto, la teoría del derecho expuesta por Hart resulta insuficiente al omitir dar cuenta de la condición necesaria de la justicia para hallar el concepto del derecho y ofrecer una teoría satisfactoria que comprenda de forma completa los elementos necesarios y suficientes del derecho y que sirva de base para el tratamiento del problema de los sujetos y grupos de especial protección; por el contrario, esa confusión teórica ha contribuido con el acrecentamiento de la problemática.

\subsection{Sujetos y grupos de especial protección en medio de la confrontación teórica: teoría excluyente, teoría de la inclusión contingente y teoría de la inclusión necesaria}

La discusión descrita con Hart es solo un punto de arranque que permite plantear que la falta de una teoría de base para los sujetos y grupos de especial protección hace parte de su problema, el cual es concebido y resuelto de manera distinta desde tres concepciones del derecho opuestas: aquella que apela a distinguir el derecho y la justicia, otra que admite una relación contingente $y$, una más, que defiende una relación necesaria entre el derecho y la justicia; todas ellas cuentan con distintos teóricos que se han enfrentado para defender o cuestionar una de las tres posiciones.

El caso de Hart es uno de los que se ha tomado como referente, porque su teoría ha sido un eje importante desde el cual han girado estas tensiones entre el derecho y la justicia. Para demostrar esta confrontación desde la mirada de otros teóricos, se pueden ver enfrentados Joseph Raz, del lado de la postura excluyente; Wilfrid Waluchow, de lado de la inclusión contingente, y Ronald Dworkin, del lado de la inclusión necesaria. ${ }^{23}$

23 A Robert Alexy también puede ubicársele en la línea de la relación necesaria, ya que a través de su Teoría de la argumentación jurídica sustenta el derecho ligado a las reglas de un discurso jurídico, a partir del discurso práctico general con una pretensión de corrección racional y justa. Según esto, la razón y la justicia no pueden trabajar aisladamente, se presupone conceptualmente el derecho como un orden social racional y justo. Esta es una manera de definir el derecho desde un contenido procedimental de la justicia, a partir de unas reglas positivas dentro de la adjudicación del derecho (Alexy, 2008, pp. 23-280). 
De esta manera, el teórico Joseph Raz no se aproxima a una concepción del derecho desde la justicia como un elemento esencial o característico de este; para Raz "las tres características más generales e importantes [del derechol son que es normativo, institucionalizado y coactivo" (2011, pp. 21 y 22). Por consiguiente Raz defiende el derecho como la razón excluyente de todas las razones, es decir, es la razón última, no hay razones subyacentes o por fuera de él, ni tampoco está apegado o justificado por razones de justicia y excluye cualquier justificación moral del derecho; para sostener su teoría, se apoya en las tesis de Kelsen, Bentham y Hart, a partir de lo cual intenta fortalecer el imperio de lo normativo y de la autoridad del derecho sin reconocer la justicia como un elemento característico, necesario y conceptualmente funcional del derecho, y en este orden, el derecho de los sujetos y grupos de especial protección puede ser desconocido sin apelación a ninguna razón de justicia, por lo cual esta base teórica resulta inapropiada para explicar el derecho y para tratar el problema de justicia de los desaventajados.

Al confrontar las posiciones de Hart y Raz, como se dijo, aparecen: por un lado, Wilfrid Waluchow (2007), ${ }^{24}$ quien apuesta a una inclusión contingente de la justicia y la moral al concepto del derecho; por el otro, Ronald Dworkin (1992), quien apela por una inclusión necesaria. ${ }^{25}$

Por su parte, Waluchow defiende la tesis del positivismo incluyente, según la cual, "es posible reconocer el rol de la moral ly la justicia] en las aplicaciones del derecho sin negar que las leyes y criterios para las leyes deben tener las conexiones institucionales apropiadas" (2007, p. 156). Así, desde esta concepción, "los valores y principios morales [como la justicia] cuentan entre los posibles fundamentos que un sistema jurídico podría aceptar para determinar la existencia y contenido de las leyes válidas" (Waluchow, 2007, p. 97).

Nótese que aquí Waluchow habla de la posibilidad de considerar la justicia o las razones morales como un elemento del derecho; pero no como

24 Wilfrid Waluchow ubica a Hart como un positivista incluyente; sin embargo, argumenta más razones para ubicarlo como un positivista excluyente, tal y como se le ha considerado en este escrito. El mismo Waluchow advierte que podría pensarse -como se hace aquí- que las influyentes razones de Hart para preferir el positivismo a la teoría del derecho natural podrían extenderse hasta proveer una base plausible para elegir el positivismo excluyente sobre el incluyente (2007, p. 99).

25 Debe aclararse que aquí no se pretende identificar a Dworkin con la corriente del positivismo incluyente, sino con su teoría de la integridad del derecho. 
una condición necesaria. Insiste en que "las razones morales [y de justicia] son a veces relevantes pero solo en la medida en que el sistema jurídico las reconoce" (2007, p. 156).

De esta forma, es innegable que hay un avance importante del positivismo jurídico al abrir la posibilidad de reconocer las razones de justicia en un sistema jurídico; sin embargo, esta posibilidad tan solo contingente no permite solucionar el problema jurídico de la relación necesaria entre el derecho y la justicia y tampoco el de los sujetos y grupos de especial protección, pues al plantearse solo como una posibilidad, termina admitiendo la existencia de ordenamientos jurídicos injustos, lo que lleva a una representación o explicación distorsionada del modo en que el derecho debe ser entendido, interpretado y aplicado, y a la posibilidad de que se admitan ordenamientos que persistan en la violación de los derechos de dichos sujetos y grupos desaventajados de la sociedad.

Ronald Dworkin va mucho más allá y propone entender el derecho como integridad, según el cual "las propuestas de ley son verdaderas si figuran o surgen de principios de justicia, equidad y debido proceso que proporcionan la mejor interpretación constructiva de la práctica legal de la comunidad" (Dworkin, 1992, p. 164); además, continúa aduciendo que "el derecho como integridad requiere que los jueces asuman, hasta donde sea posible, que el derecho está estructurado por un conjunto coherente de principios sobre justicia, equidad y debido proceso y que los hagan cumplir" (p. 175).

El derecho, así visto, es una práctica interpretativa de lo justo que permite reivindicar la relación necesaria entre el derecho y la justicia. En ese sentido, la teoría de la integridad se convierte en una de las que mejor permite explicar esta relación que, a su vez, rompe con el paradigma del positivismo excluyente. Dworkin nos lleva a concebir el derecho en cadena, en una constante construcción interpretativa y coherente del derecho a partir de la historia de los casos concretos y del principio de la moralidad pública vigente que le permite al juez hallar la mejor decisión que, conforme con el máximo principio de justicia, muestre su mejor perspectiva posible (Dworkin, 1992, pp. 164-197). Dworkin concluye que el derecho:

[...] es un concepto interpretativo no agotado por ningún catálogo de reglas o principios [...] $\mathrm{Ni}$ tampoco por un grupo de funcionarios $\mathrm{y}$ sus poderes [...]. Es la actitud lo que define el imperio de la justicia (del 
derecho) y no el territorio, el poder o el proceso. [...] Es una actitud interpretativa y [...] es constructiva: su objetivo, es el espíritu interpretativo, es colocar el principio [justicia] por encima de la práctica para demostrar el mejor camino hacia un futuro mejor, cumpliendo con el pasado (1992, pp. 289 y 290).

En este sentido, compartiendo con Dworkin que el derecho es un concepto interpretativo y la justicia también lo es, se argumenta que el derecho se explica de la mejor manera conceptual y sustancialmente correcta a partir, primero, de reconocer su fundamento moral en la justicia, ${ }^{26}$ es decir, el derecho tiene una naturaliza valorativa, existe porque desde su concepción está fundado en la consideración de que es bueno para la justicia social y, segundo, desde el argumento funcional del concepto del derecho. ${ }^{27}$ Esto quiere decir que el derecho tiene intrínsecamente unos elementos funcionales que permiten identificar específicamente los rasgos de su concepto, así como para Hart lo eran las reglas para responder a la presión social y al cambio, para Raz lo son la guía de la conducta pública y la autoridad (Leiter, 2012, p. 177). Aquí se destaca la justicia como el más importante entre ellos.

El derecho tiene en todos los sistemas jurídicos un contenido mínimo de justicia como función, límite y criterio interpretativo de corrección del sistema jurídico, bien sea en aquellos sistemas formados consuetudinariamente o por reglas, o por principios o en aquellos que los contenga a todos,

26 Este argumento del fundamento moral del concepto del derecho lo tomo de Fernando Atria, pero situado en un extremo distinto al de su teoría, ya que él fundamenta una versión del positivismo ético del derecho que se opone a la discusión central que aquí se discute; sin embargo, se toma de él la idea de explicar el concepto del derecho desde el fundamento ético. Atria sostiene que "el derecho existe porque (colectivamente) creemos que existe. Por lo tanto, nuestras creencias sobre cómo es el derecho [...]" son en parte creencias sobre cómo sería bueno que el derecho fuera. Por tanto, defiende la versión del positivismo ético sobre el derecho legalista porque cree que así concebido es bueno para la democracia. Pues bien, aquí se defiende que una comprensión correcta del derecho es imposible hacerla de forma avalorativa, es decir, que no existe en el mundo con independencia de nuestras creencias sobre él, el derecho que es, tiene fundamento en una creencia colectiva, aquí se considera que esa creencia es en el valor de la justicia, esta es la mejor forma de entender y explicar el derecho: el derecho que es bueno debe ser bueno para la justicia social (Atria, 2004, p. 135).

$27 \mathrm{El}$ argumento funcional lo apoyo en Brian Leiter, quien permite inferir que el concepto del derecho, particularmente, se ve atado a nuestro concepto de las funciones que tiene este, pues proporcionan la mejor explicación de los rasgos relevantes que pretendidamente forman parte del concepto del derecho. En este sentido, Leiter destaca el carácter pragmático de las normas, su valor práctico, en cuanto sean útiles para los propósitos y fines humanos; es decir, que funcionen de acuerdo con ellos (Leiter, 2012, pp. 87-91). 
incluidos los valores; por ello se ha sostenido en este escrito que conociendo el concepto interpretativo de la justicia, hallamos una parte esencial de las funciones y elementos necesarios del derecho y la clave para fundamentar los derechos de los sujetos y grupos de especial protección.

Así, toda teoría del derecho para que sea correcta y completa debe dar cuenta de esta relación necesaria entre el derecho y la justicia y, para ello, se considera importante y de gran utilidad que esta se sirva de las teorías de la justicia, porque comprendiendo su significado y los principios que la gobiernan, puede explicarse de una mejor manera esta función del derecho y principalmente su concepto.

Con base en las anteriores teorías, se defiende la posición propuesta por Ronald Dworkin y Robert Alexy, quienes sostienen la relación necesaria entre el derecho y la justicia en la concepción del derecho, ${ }^{28}$ en la cual aparece una base teórica adecuada para los sujetos y grupos de especial protección en defensa, garantía y exigibilidad de sus derechos en el ordenamiento jurídico; por otro lado, se aparta de las posiciones excluyentes o contingentes de Hart, Raz y Waluchow y los otros teóricos que siguen estas líneas.

\section{El problema de la falta de fundamentación teórica de la justicia en el derecho versus una apuesta por la pluralidad de significados de la justicia en el derecho para los sujetos y grupos de especial protección}

Este título aborda la segunda cuestión problemática de fondo en el marco de los sujetos y grupos de especial protección, esto es, el problema no se queda en la ausencia de una teoría de base del derecho colombiano que omite esa relación necesaria entre el derecho y la justicia sino que, a su vez, genera una falta de fundamentación teórica de la justicia dentro del

28 Así también lo sostiene el profesor Roberto Gargarella, quien en una entrevista concedida al autor de este escrito sobre el problema de la especial protección y, directamente, sobre la tesis planteada de la relación necesaria entre el derecho y la justicia advierte que no le asiste duda en la veracidad de esta afirmación, por cuanto esta cuestión no debe seguir constituyendo un problema para la teoría del derecho. Admitir por lo tanto esta presuposición permite avanzar en los problemas teórico-prácticos que le plantea la justicia social al derecho (Gargarella, comunicación personal, Buenos Aires, 8 de agosto de 2014). 
derecho y una incertidumbre sobre lo justo dentro de este objeto jurídico de la especial protección.

Quiere decir lo anterior que la separación del derecho y la justicia desemboca en una seria ausencia de esta última en el contenido de las normas del ordenamiento jurídico, en las prácticas del derecho estatal y en una pérdida de sus significados en el contexto colombiano para brindar soluciones reales y justas a la diversidad de problemáticas que hay en la pluralidad de los sujetos y grupos de especial protección.

Así también, cuando esa separación se presenta de manera contingente y se da la idea de que en el derecho colombiano puede haber lugar para la justicia de manera eventual, siempre que la regla de derecho así lo establezca en algunos casos, ocurre que, por un lado, se normaliza la justicia bajo un solo significado que es el formal del derecho estatal, cuyas aproximaciones y remedios son unidimensionales, institucionales y carentes de una fundamentación teórica adecuada a las circunstancias especiales de los sujetos y grupos de especial protección, con lo cual se desconoce la pluralidad de enfoques teóricos y significados de la justicia que deben ser tenidos en cuenta en esa relación con el derecho; por otro lado, esa eventualidad de la justicia es vista como un instrumento de poder del Estado para mantener el statu quo, los privilegios en unos y la dominación sobre otros, lo que en ambos casos se convierte en el segundo foco principal de la problemática del objeto jurídico de la especial protección, más que en una solución adecuada.

Lo anterior nos lleva a plantear la necesidad de llenar este vacío teórico que existe en el derecho sobre qué es lo justo en materia de especial protección y defender la tesis de la pluralidad de significados de la justicia ${ }^{29}$ para los sujetos y grupos de especial protección en el marco de su relación necesaria con el derecho colombiano. A partir de allí se argumenta que

29 Abordar la pluralidad de significados de la justicia tiende a sostener que no hay un único significado, pese a que de esta manera se pretenda postular por los teóricos de la justicia. En este sentido, el caso de los sujetos y grupos de especial protección resulta particularmente revelador, en la medida en que de acuerdo con sus particulares situaciones y clasificaciones como las destacadas al principio de este artículo en grupos de especial protección: 1) por sus circunstancias físicas, 2) condiciones psicológicas, 3) víctimas de violencia generalizada, 4) tradicionalmente discriminados y 5) en condiciones de pobreza, marginalidad y territorialidad, llevan a sustentar la imposibilidad de encajar el tratamiento de todos estos en una sola noción y la necesidad de estudiar, dentro de la diversidad de nociones, aquellas que resulten más adecuadas a la pluralidad de los sujetos de especial protección. 
este objeto jurídico reviste, en sí mismo, diversos contenidos de justicia que requieren ser descubiertos según cada caso, lo cual es adecuado verlo a la luz de las conocidas teorías contemporáneas de la justicia, ${ }^{30}$ que se han dedicado al estudio del tema; entre las cuales se destacan las expuestas por John Stuart Mill, John Rawls, Amartya Sen, Iris Marion Young, Rodrigo Uprimny y Diana Esther Guzmán. ${ }^{31}$

Estas teorías permiten conocer la diversidad de concepciones de la justicia en el tratamiento de estos sujetos y grupos que, en cada caso, es definida y diferenciada a partir de la apuesta por ciertos principios que caracterizan y determinan los contenidos de la justicia y que pueden resultar admitidos o rechazados dentro de una teoría de la especial protección en el derecho colombiano.

John Stuart Mill (1980), por su parte, propone una teoría utilitarista de la justicia consistente en lograr el principio de la mayor felicidad para el mayor número de personas. Así, una sociedad justa es aquella que promueve la mayor felicidad para toda la comunidad, y esta, así mismo, es entendida como la búsqueda de aquello placentero y desarrolla el intelecto humano y la dignidad como seres racionales y evita el dolor, pero también es el sacrificio de los intereses individuales o placeres inferiores en razón a un fin mayor, que es el interés general representado en la elección mayoritaria de lo que es correcto, lo cual limita o posibilita la libertad de los individuos conforme con el interés de las mayorías.

La justicia debe garantizar la mayor felicidad a favor de la sociedad en general y el bien común, y la minoría debe acogerse a ello, promoviendo así la utilidad y no el egoísmo, la racionalidad instrumental, el interés general, la tranquilidad, los estímulos, la seguridad, la igualdad, la educación, los

30 Estas teorías no son las únicas que se han dedicado al estudio de la justicia, pero son las que cuentan con mayor reconocimiento y debate en nuestro contexto colombiano y en la comunidad académica, en los programas de teorías contemporáneas de la justicia en las facultades de derecho y de filosofía, y en los programas de maestría y doctorado. Pero principalmente han sido escogidas porque son las más importantes en la problematización de los sujetos y grupos de especial protección.

31 Otras teorías de justicia que deben ser tenidas en cuenta en el campo de la especial protección son la propuesta por Honneth (1992), a partir de la cual se sustenta una teoría del reconocimiento recíproco que se explica con fundamento en el conflicto moral que surge en la lucha social del individuo por la defensa de su individualidad o su propio yo o su diferencia, y por Nancy Fraser, quien apela a una teoría de la justicia que dé cuenta de reivindicaciones en reconocimiento, pero también reivindicaciones en redistribución; es decir, toda teoría de justicia frente a sujetos y grupos de especial protección debe tener en cuenta que sus demandas de justicia envuelven siempre reivindicaciones de estatus y reivindicaciones de clase (Fraser y Honneth, 2003). 
valores superiores, las oportunidades de todos y evitar al máximo el dolor de la colectividad. Por ello reconoce que cuando se juzga una conducta justa, no es la propia felicidad del que obra -lo que se tiene en cuenta-, sino la de todos, porque el utilitarismo exige a cada uno que entre su propia felicidad y la de los demás, sea un espectador tan estrictamente imparcial como desinteresado y benevolente (Mill, 1980, pp. 138-155).

Esta teoría, en principio, parecería ofrecer interpretaciones desfavorables que no permitirían asegurar condiciones ideales de justicia para los sujetos y grupos de especial protección: primero, porque el criterio de la mayoría o el interés general no resuelve el problema de estos en sociedades donde son tenidos como minorías; segundo, porque presupone valores superiores en la idea del desarrollo del intelecto humano, desconociendo sujetos como los de especial protección que por sus distintos factores no tienen la posibilidad de aspirar y alcanzar esos intereses, y, tercero, porque ese principio de la felicidad les estaría vedado de entrada, pues al carecer probabilísticamente de esos valores superiores, estarían permanentemente expuestos a ser sacrificados a favor de la mayoría que goza de dichos valores.

De cara a la justicia igualitaria planteada en el caso colombiano, se parte de la idea del valor esencial de cada individuo como un fin en sí mismo, cuestión fundamental que desconoce esta teoría, ya que bajo su perspectiva las minorías serían un medio para el logro de la felicidad de la mayoría, lo que iría en contra especialmente de los más débiles como los sujetos de especial protección.

No obstante, no debe desconocerse que dentro de los principios generales del derecho colombiano se privilegia el interés general sobre el particular, como una manifestación de esta teoría utilitarista; sin embargo, vale señalar que en todo caso la aplicación de este principio debe ser considerada de manera general, donde existen condiciones de igualdad real entre los sujetos iguales, y también debe ser interpretada de forma que no lesione o ponga en peligro el núcleo esencial de la dignidad de los individuos, en cuanto fines en sí mismos.

Estas consideraciones obligan a no tener en cuenta esta teoría, por cuanto no proporciona su mejor cara para la concepción de la justicia en contextos de profundas desigualdades sociales e innumerables casos de especial protección y exige revisar que otras teorías sí miren estas cuestiones. 
John Rawls, por su parte, propone una teoría de la justicia que busca la equidad. Señala que:

[...] el objeto primario de la justicia es la estructura básica de la sociedad [...], el modo en que las grandes instituciones sociales distribuyen los derechos y los deberes fundamentales y determinan la división de las ventajas provenientes de la cooperación social. Dichas instituciones favorecen ciertas posiciones iniciales en la vida [...] es a estas desigualdades [...] inevitables, a las que deben aplicar en primera instancia los principios de justicia social. [...] la justicia de un esquema social depende esencialmente de cómo se asignan los derechos y deberes fundamentales, y de las oportunidades económicas y las condiciones sociales en los diversos sectores de la sociedad. Por tanto, una concepción de la justicia social ha de ser considerada como aquella que proporciona, en primera instancia, una pauta con la cual evaluar los aspectos distributivos de la estructura básica de la sociedad (Rawls, 2006, pp. 20-23).

A partir de allí, Rawls define la justicia como "el papel que juega un conjunto de principios relacionados entre sí, para identificar las consideraciones pertinentes que hacen posible ese equilibrio entre pretensiones enfrentadas y la división correcta de las ventajas sociales" (2006, pp. 20-23).

Para Rawls una concepción de la justicia debe, fundamentalmente, aplicar dos principios o materiales que, sopesados, en cada caso, llevan a su realización: el primero de ellos es garantizar igual libertad para todos y el segundo es la igualdad equitativa para todos, apelando al principio de diferencia que implica rechazar las desigualdades arbitrarias a no ser que sea razonable esperar que redunden en provecho de todos y sean accesibles a todos, es decir, se debe rectificar esas desigualdades naturales y sociales, garantizando que quienes se encuentren en una mejor situación deben favorecer a los menos favorecidos (2006, pp. 58-88).

Esta teoría nos muestra una mejor cara para los sujetos y grupos de especial protección ${ }^{32} \mathrm{y}$, en principio, coincide con algunos de los presupuestos

32 Según expresa Roberto Gargarella, la apuesta de Rawls por "una sociedad justa necesita de un Estado muy activista - un Estado cuyas instituciones fundamentales [deben] contribuir en la primordial tarea de igualar a las personas en sus circunstancias básicas" (1999, p. 45). Tal concepción apela al criterio de igualdad para alcanzar la justicia social, tal y como se propone en el caso colombiano con el artículo 13 de la Constitución Política. 
de la justicia colombiana, especialmente cuando se refiere a la igualdad equitativa para todos y a la rectificación de las desigualdades naturales y sociales.

Tal afirmación lleva a plantear algunas cuestiones fundamentales: primero, la igualdad como equidad suele ser una apuesta muy loable para el contenido de la justicia en el caso bajo estudio y, por tanto, la especial protección debe ser fundamentada desde esta perspectiva, donde hay un interés por el individuo, sus bienes materiales y su distribución equitativa con los demás; pero, además, el primer principio que superpone Rawls de iguales libertades para todos permite reconocer la principal de las limitaciones que tienen los menos favorecidos para actuar y determinarse libremente, esto es, que no todos tienen iguales libertades y, desde allí, pueden derivarse las principales razones para hablar de una teoría de especial protección, lo que hace que la teoría de Rawls sea trascendente para el estudio de esta problemática.

Segundo, de cara al principio de diferencia hay un interés por la corrección de las desigualdades naturales y sociales entre los individuos, lo cual también abre la puerta para la admisibilidad de una teoría de los sujetos y grupos de especial protección, en tanto que a través de este se obliga a reconocer la existencia de diferencias injustas entre los sujetos que no les son imputables, dependen del azar, la naturaleza o la sociedad y, por tal razón, quienes se encuentran en una mejor posición están obligados a asumir las cargas de dicha corrección. En este sentido, este principio es una autorización y un llamado para atender las desigualdades injustas que constituyen la causa de las especiales circunstancias en que se encuentran los sujetos desaventajados y brindar una protección reforzada.

Ahora bien, cuando se mira la justicia bajo la noción de Rawls, la igualdad equitativa no significa propiamente que haya una igualación distributiva de los derechos al punto de equipararlos entre los sujetos que ostentan una mejor situación y los menos favorecidos; quiere decir que estos últimos deben ser protegidos al punto de eliminar las diferencias que los hace menos favorecidos frente a los otros, mas no se trata de una igualación matemática.

Esta teoría de la justicia aporta estos dos principios que definen un contenido instrumental de lo justo para la realización de los derechos de especial protección; sin embargo, no es ajena al peligro de quedarse como una teoría del deber ser, donde los principios de igual libertad y diferencia 
pueden caer en ciertos formalismos que no conducen a la concepción de la justicia como igualdad material.

Una tercera teoría es destacada en Amartya Sen, quien considera que las anteriores concepciones de justicia de John Mill y John Rawls son muy limitadas; en su opinión, la justicia requiere considerar el principio de las libertades fundamentales, entendidas como las capacidades para elegir la vida que tenemos razones para valorar; principio que parte de una base de información más amplia, que centra su atención en las capacidades de los individuos (Sen, 2000, pp. 78 y 79). Sostiene, además, que la justicia debe mirarse no en abstracto, sino que debe fijarse:

[...] en los medios que tiene un individuo para vivir bien, centrar su atención en la vida real que consiguen los individuos [...] o en la libertad [que tienen] para conseguir la vida real. Afirma además que la capacidad es un tipo de libertad: la libertad fundamental para conseguir [distintas cosas que una persona puede valorar hacer o ser], la libertad para lograr diferentes estilos de vida (Sen, 2000, pp. 97-100).

Por tanto, la justicia debe valorar "(lo que una persona es capaz de hacer realmente) o el conjunto de capacidades de las opciones que tiene (sus oportunidades reales)" y a partir de allí debe juzgar sus actos y garantizar la mayor realización de las capacidades que tiene un individuo (Sen, 2000, p. 100).

A partir de allí existe un avance teórico en la concepción de la justicia para los sujetos y grupos de especial protección, ya que esta noción aporta un nuevo principio - el de las capacidades-, que debe tenerse en cuenta en cada caso, pues a partir de este se trata la justicia bajo elementos antes no clarificados; esto es, la vida real y las capacidades como expresión de las libertades de los individuos.

Así, este avance en la noción de la justicia se logra percibir en su instrumentalización y materialización, a partir de la idea de clasificación de los sujetos de especial protección de acuerdo con sus diferentes capacidades, la revisión del contexto en las decisiones judiciales y la valoración y ponderación en cada caso concreto. ${ }^{33}$

33 No obstante, en todo caso se debe tener cuidado con el concepto y contenido de capaci- 
A más de lo anterior, hay que resaltar que bajo esta idea de la justicia existe un escenario muy valioso por explorar en el ámbito legislativo y ejecutivo sin dejar atrás su aplicación en lo judicial; en estos campos, se debe seguir considerando las condiciones particulares de cada individuo como un fin en sí mismo y trascender hacia un modelo de lo justo que respete y proteja las diferentes capacidades de los sujetos y propenda por acciones positivas para su beneficio propio y colectivo.

Así, avanzando en la concepción de la justicia como un asunto complejo, es prioritario abordar en otras teorías que permitan ampliar, aún más, su comprensión y construcción de cara a la especial protección. Aparece entonces una cuarta teoría en Iris Marion Young, quien defiende la idea de justicia a partir del principio de inclusión y política de la diferencia de grupos oprimidos, que es una concepción de la justicia no en un sentido distributivo solamente, sino que permite hacer cosas y, en este sentido, también debe referirse "a las condiciones institucionales necesarias para el desarrollo y el ejercicio de las capacidades individuales, la comunicación colectiva y la cooperación" (Young, 2003, p. 71).

En este sentido, Young sostiene que la justicia debe enfocarse en solucionar los problemas de la opresión que padecen los individuos por pertenecer de manera agregativa o asociativa a un cierto grupo social, que los lleva a sufrir "una limitación en sus facultades para desarrollar y ejercer sus capacidades y expresar sus necesidades, pensamientos y sentimientos" (2003, p. 73).

En este orden, propone identificar las caras de la opresión sobre las condiciones de los grupos que están "oprimidos: entre otros, las mujeres, la gente negra, [...] la gente indígena, [...] las lesbianas, los hombres gay, [...] las personas ancianas, la gente de clase obrera y los discapacitados físicos y mentales" (Young, 2003, pp. 72 y 73).

Concluye que dichas caras provienen de diferentes formas de opresión: la explotación, la marginación, la carencia de poder, el imperialismo cultural y la violencia. Así, el problema de la justicia tiene raíces en estructuras formadas por instituciones sociales, económicas, de división del trabajo y culturales.

dades propuesto por Sen, ya que en el contexto colombiano esa noción de capacidades debe ser recibida, pero interpretada de acuerdo con cada de sujeto y grupo de especial protección, ya que entre ellos dicha concepción es diferente. 
La justicia debe proveer las condiciones para evitar y reducir esas caras de la opresión frente a los grupos (Young, 2003, pp. 71-113).

Esta teoría permite contemplar una concepción de la justicia cercana a los sujetos y grupos de especial protección, en la medida en que estos entran a ser considerados los sujetos oprimidos socialmente $\mathrm{y}$, a partir de allí, se revelan las estructuras institucionales y sociales que constituyen las causas de las injusticias que deben ser corregidas en cada caso; por lo tanto, esta teoría hace un aporte en la noción de la justicia desde una perspectiva de los sujetos débiles, que sobrepasan las teorías retributivas y ponen el relieve en el reconocimiento de los criterios que oprimen a los sujetos de especial protección, sus limitaciones y cargas injustas y las estrategias que deben ser tomadas para la erradicación de la opresión y el logro de la justicia material.

En esta dirección, se trae como aporte central en la noción de la justicia el principio de inclusión y política de la diferencia de grupos oprimidos, conforme a la cual se apela a liberar a los sujetos y reincorporarlos al orden social en igualdad de condiciones que el resto de individuos.

Finalmente, una quinta concepción de la justicia se puede ver con Rodrigo Uprimny y Diana Esther Guzmán (2010), quienes proponen una teoría de la justicia en escenarios de transición, la cual es concebida bajo el principio de restitución plena o reparación integral y transformadora a las víctimas de violaciones graves y masivas a sus derechos humanos, mediante el cual se defiende la idea de implementar:

[...] reparaciones transformadoras que tienen en cuenta sus contextos transicionales, en especial, en sociedades con desigualdades profundas y pobreza extendida, dando respuesta a los requerimientos de la justicia distributiva y de participación de las comunidades victimizadas, valorizando su perspectivas desde abajo (p. 238).

Esta noción de la justicia apunta a considerar programas de reparación:

[...] que tienen como propósito esencial, al menos en teoría, resarcir el daño y restaurar a la víctima, hasta donde sea posible, a las condiciones que gozaba antes de que el daño ocurriera. [...]. Así como también deben contener una inevitable dimensión simbólica, ya que los daños suelen ser irreparables, y de otro lado, procurar a través de las reparaciones transformadoras, no restaurar a las víctimas pobres a su situación previa de pre- 
cariedad material y de discriminación, sino transformar esas circunstancias (Uprimny y Guzmán, 2010, pp. 240-253).

Esta perspectiva que se destaca también interesa a la noción de la justicia, en la medida en que es una concepción que apunta a una propuesta teórica que se conecta más específicamente con la categoría de sujetos de especial protección víctimas de la violencia generalizada y, en esa medida, constituye una propuesta focal a este problema; pero que se proyecta hacia las demás categorías de los otros grupos, ya que no solo busca reparar los hechos que los hace víctimas, sino también atender otras causas que los hace vulnerables y que, de no tratarlas, los sigue dejando en otras situaciones de vulnerabilidad y especial protección, que les impide ascender a un estado justo de igualdad social.

Así, Colombia - como otros países que viven estos contextos de violencia- debe considerar que la noción de justicia, en el caso de las víctimas de violaciones graves y masivas a los derechos humanos, no puede concebirse de manera recortada, dirigida solo a la reparación de los daños producidos por la violencia, sino que debe adoptarse una noción completa que tenga en cuenta, además, las otras situaciones de injusticia que los hace sujetos de especial protección, con el fin de transformar esos hechos en nuevas condiciones reales de justicia e igualdad.

En este orden de ideas, la anterior fundamentación teórica - desde sus distintas acepciones de la justicia- permite concluir que lo justo frente al problema de los sujetos y grupos de especial protección tiene diferentes significados que no pueden mirarse desde una única teoría de la justicia, ni siempre de manera excluyente; esto es, la variedad de significados de la justicia permite tratar a cada sujeto y grupo de especial protección de una manera más cercana a la realidad de su problemática, de acuerdo con el enfoque de una u otra noción de justicia.

Así, por ejemplo, puede verse que, en el caso de los sujetos en condiciones de pobreza, marginalidad y precariedad económica, se tiene la teoría de Rawls que aplica los principios de igual libertad para todos e igualdad equitativa para todos. En los sujetos de especial protección, por sus circunstancias físicas o sicológicas, puede resultar más ajustada la teoría propuesta por Amartya Sen, con su principio de las libertades fundamentales, centrado en las capacidades de los individuos. Frente a los sujetos 
socialmente discriminados, es adecuada la teoría de Iris Marion Young, con su principio de inclusión y política de la diferencia de grupos oprimidos, y en el caso de las víctimas de la violencia generalizada, estaría la propuesta por Rodrigo Uprimny y Diana Guzmán, con su principio de restitución plena o reparación integral y transformadora.

\section{Consideraciones finales}

El Estado colombiano tiene que reinventar el derecho de la especial protección e iniciar por reconstruir este objeto jurídico a partir de la idea de un derecho ampliado que establezca una justicia dialógica entre el legislador, los jueces, los órganos de la administración pública, los sujetos y grupos de especial protección y los demás actores sociales que participan en el contexto social en la construcción y defensa de los derechos especiales, con el fin de acercar los diferentes discursos del derecho estatal y los discursos de derecho ampliado que vienen de las bases sociales. Esto es clave para enfrentar los problemas que presenta actualmente el derecho excepcional, asimétrico, desarticulado y encerrado en las fuentes formales que producen los órganos del Estado respecto de los sujetos y grupos de especial protección.

La idea de reconstruir este objeto jurídico tiene que ir más allá de adoptar las estrategias centralizadas y tradicionales del Estado de establecer una posible codificación de la especial protección, que hoy en el ordenamiento jurídico colombiano no existe, pues - como se mostró al inicio- hay una excesiva legislación formal, abstracta y dispersa que oscurece la materia, y su recogimiento en un código parece ser una opción meramente formal, cerrada y excluyente capaz de crear un nuevo artificio de la especial protección; tampoco recurrir a los innumerables precedentes judiciales de la Corte Constitucional colombiana, pues esta vía es excepcional, lenta y se queda corta para atender la magnitud de la problemática y la diversidad y pluralidad de los sujetos y grupos que demandan legítimamente su especial protección. Por otro lado, tampoco puede depender de las crecientes reglamentaciones del Ejecutivo que, por lo general, derivan en nuevas tecnologías de gobierno, que más que brindar una protección ajustada a 
las necesidades de estos sujetos y grupos, han servido para mantener su realidad en las mismas condiciones desprotección.

En este sentido, el derecho de la especial protección implica que sea tratado como un problema urgente de relación necesaria entre el derecho y la justicia, que obliga, ante todo, como quedó expuesto, a replantear las bases teorías del derecho y a nutrirlo de diversos contenidos de justicia, que respondan a las necesidades de protección que reclaman, en cada caso, los sujetos y grupos de especial tratamiento.

El discurso del derecho estatal en Colombia, en general, y sobre los sujetos y grupos de especial protección, en particular, como se ha planteado, debe empezar por reorientarse. Este no puede quedarse anclado en el positivismo jurídico tradicional que ha sido dominante en la sociedad colombiana y que ha servido en la práctica para justificar una manera de concebir el derecho desligado de su relación necesaria con la justicia.

Entender el derecho en su relación necesaria con la justicia implica construir un nuevo discurso de la especial protección que parta de la base social, en el cual el Estado participe no de manera impositiva, excepcional y asimétrica, sino de forma pluralista, coordinada y dialógica, donde la diversidad de perspectivas de la justicia debe ser el norte que guíe el contenido de los derechos que pueden acercarse a una real protección de los sujetos y grupos especialmente necesitados de protección.

\section{Referencias}

Alexy, R. (2008). Teoría de la argumentación jurídica: la teoría del discurso racional como teoría de la fundamentación jurídica. Madrid: Editorial Centro de Estudios Políticos y Constitucionales.

Atria, F. (2004). La ironía del positivismo jurídico. DOXA, Cuadernos de Filosofía del Derecho, 27, 473.

Balakrishnan, R. (2008). Invoking the rule of law in post-conflict rebuilding: A critical examination. William and Mary Law Review, 49(4), 1345-1374.

Cifuentes, E. (2014). Sujetos de especial protección en la Constitución Política. Barranquilla: Universidad Libre.

Congreso de la República de Colombia. Tercera edad: 50 (1990), 105 (1993), 160 (1994), 223 (1995), 333 (1996), 400 (1997), 490 (1998), 508 (1999), 599 
(2000), 629 (2001), 789 (2002), 820 (2003), 915 (2004), 1101 (2006), 1151 (2007), 1251 (2008), 1341 (2009), 1417 (2010), 1482 (2011), 1593 (2012), 1617 (2013). Campesinos: 4 (1990), 14 (1991), 104 (1993), 161 (1994), 223 (1995), 333 (1996), 418 (1997), 534 (1999), 611 (2000), 789 (2002), 812 (2003), 1152 (2007), 1448 (2011), 1564 (2012), 1622 (2013). Damnificados: 45 (1990), 104 (1993), 241 (1995), 340 (1996), 418 (1997), 782 (2002), 1066 (2006), 1152 (2007), 1430 (2010), 1488 (2011), 1523 (2012). Desaparecidos: 45 (1990), 11 (1992), 81 (1993), 137 (1994), 222 (1995), 356 (1997), 406 (1997), 472 (1998), 522 (1999), 609 (2000), 721 (2001), 733 (2002), 769 (2002), 836 (2003), 877 (2004), 991 (2005), 1121 (2006), 1142 (2007), 1268 (2008), 1336 (2009), 1426 (2010), 1478 (2011), 1592 (2012), 1675 (2013). Desplazados: 111 (1994), 188 (1995), 265 (1996), 368 (1997), 443 (1998), 508 (1999), 590 (2000), 715 (2001), 785 (2002), 833 (2003), 909 (2004), 975 (2005), 1112 (2006), 1152 (2007), 1268 (2008), 1304 (2009), 1380 (2010), 1450 (2011). Diversidad-diversidad Sexual-LGBTI: 21 (1991), (1992), 99 (1993), 165 (1994), 218 (1995), 304 (1996), 411 (1997), 464 (1998), 536 (1999), 600 (2000), 715 (2001), 768 (2002), 850 (2003), 906 (2004), 1000 (2005), 1109 (2006), 1166 (2007), 1268 (2008), 1360 (2009), 1412 (2010), 1493 (2011), 1601 (2012), 1670 (2013). Enfermos: 56 (1990), 17 (1991), 100 (1993), 171 (1994), 320 (1996), 380 (1997), 522 (1999), 599 (2000), 715 (2001), 767 (2002), 916 (2004), 949 (2005), 1164 (2007), 1268 (2008), 1414 (2010), 1435 (2011), 1517 (2012), 1616 (2013). Extranjeros: 49 (1990), 17 (1991), 31 (1992), 106 (1993), 172 (1994), 251 (1995), 340 (1996), 412 (1997), 488 (1998), 526 (1999), 633 (2000), 703 (2001), 788 (2002), 864 (2003), 938 (2004), 996 (2005), 1121 (2006), 1180 (2007), 1232 (2008), 1349 (2009), 1430 (2010), 1493 (2011), 1607 (2012), 1673 (2013). Gitanos: 812 (2003), 1151 (2007), 1189 (2008), 1342 (2009), 1381 (2010), 1450 (2011), 1530 (2012). Indígenas: 21 (1991), 145 (1994), 188 (1995), 482 (1998), 992 (2005), 1020 (2006), 1151 (2007). Invalidez, disminuido-discapacitado: 49 (1990), 27 (1992), 106 (1993), 174 (1994), 241 (1995), 345 (1996), 418 (1997), 490 (1998), 549 (1999), 608 (2000), 715 (2001), 789 (2002), 863 (2003), 938 (2004), 1000 (2005), 1112 (2006), 1170 (2007), 1268 (2008), 1371 (2009), 1430 (2010), 1448 (2011), 1607 (2012). Juventud: 18 (1991), 65 (1993), 150 (1994), 237 (1995), 344 (1996), 397 (1997), 482 (1998), 547 (1999), 624 (2000), 768 (2002), 862 (2003), 978 (2005), 1098 (2006), 1151 (2007), 1189 (2008), 1336 (2009), 1475 (2011), 1599 (2012), 1622 (2013). Mujeres: 21 (1991), 5 (1992), 82 (1993), 171 (1994), 248 (1995), 333 (1996), 387 (1997), 488 (1998), 516 (1999), 
590 (2000), 691 (2001), 789 (2002), 860 (2003), 923 (2004), 994 (2005), 1109 (2006), 1152 (2007), 1268 (2008), 1670 (2013). Madre cabeza de familia: 3 (1991), 82 (1993), 136 (1994), 333 (1996), 387 (1997), 508 (1999), 790 (2002), 861 (2003), 906 (2004), 1152 (2007), 1232 (2008), 1429 (2010), 1469 (2011), 1551 (2012), 1632 (2013). Mujer en estado de embarazo: 50 (1990), 65 (1993), 248 (1995), 320 (1996), 347 (1997), 443 (1998), 516 (1999), 599 (2000), 742 (2002), 841 (2003), 909 (2004), 984 (2005), 1098 (2006), 1151 (2007), 1268 (2008), 1350 (2009), 1418 (2010), 1468 (2011), 1564 (2012), 1622 (2013). Mendicidad: 4 (1991), 100 (1993), 136 (1994), 188 (1995), 344 (1996), 413 (1997), 482 (1998), 547 (1999), 599 (2000), 714 (2001), 780 (2002), 848 (2003), 985 (2005), 1098 (2006), 1276 (2009), 1588 (2012). Negritudes: 70 (1993), 218 (1995), 261 (1996), 359 (1997), 463 (1998), 508 (1999), 722 (2001), 1000 (2005), 1042 (2006), 1152 (2007), 1251 (2008), 1669 (2013). Niños, niñas y adolescentes: 18 (1990), 21 (1991), 11 (1992), 100 (1993), 173 (1994), 248 (1995), 335 (1996), 418 (1997), 469 (1998), 515 (1999), 633 (2000), 724 (2001), 789 (2002), 833 (2003), 906 (2004), 994 (2005), 1109 (2006), 1171 (2007), 1268 (2008), 1359 (2009), 1421 (2010), 1503 (2011), 1607 (2012), 1670 (2013). Refugiados: 33 (1990), 12 (1991), 11 (1992), 137 (1994), 320 (1996), 469 (1998), 525 (1999), 800 (2003), 898 (2004), 1108 (2006), 1349 (2009), 1407 (2010), 1604 (2012). Victimas: 11 (1992), 104 (1993), 188 (1995), 418 (1997), 986 (2005), 1098 (2006), 1448 (2011), 1596 (2012).

Constitución Politica de Colombia de 1991. Bogotá: Legis.

Corte Constitucional de Colombia. C185 (1999), C891 (2002), C991 (2004), C54 (2005), C59 (2005), C113 (2005), C180 (2005), C-203 (2005), C-381 (2005), C-534 (2005), C-674 (2005), C-707 (2005), C-1192 (2005), C-1262 (2005), C-355 (2006), C-664 (2006), C-716 (2006), C-862 (2006), C-989 (2006), C-78 (2007), C-278 (2007), C-294 (2007), C-338 (2007), C-342 (2007), C-491 (2007), C-653 (2007), C-720 (2007), C-932 (2007), C-951 (2007), C-1000 (2007), C-1003 (2007), C-1041 (2007), C-34 (2008), C-318 (2008), C-463 (2008), C-507 (2008), C-540 (2008), C-740 (2008), C-838 (2008), C-842 (2008), C-857 (2008), C-862 (2008), C-864 (2008), C-901 (2008), C-904 (2008), C-1065 (2008), C-1186 (2008), C-1198 (2008), C-149 (2009), C-240 (2009), C-289 (2009), C-372 (2009), C-406 (2009), C-428 (2009), C-442 (2009), C-443 (2009), C-444 (2009), C-468 (2009), C-640 (2009), C-662 (2009), C-663 (2009), C-684 (2009), C-727 (2009), C-793 (2009), C-795 (2009), C-850 (2009), C-853 (2009), C-892 (2009), C-14 (2010), C-55 (2010), C-145 (2010), C-173 (2010), C-184 (2010), 
C-252 (2010), C-288 (2010), C-302 (2010), C-317 (2010), C-775 (2010),

C-776 (2010), C-830 (2010), C-840 (2010), C-029 (2011), C-221 (2011),

C-300 (2011), C-397 (2011), C-398 (2011), C-438 (2011), C-539 (2011),

C-577 (2011), C-620 (2011), C-629 (2011), C-748 (2011), C-791 (2011),

C-824 (2011), C-876 (2011), C-900 (2011), C-936 (2011), C-027 (2012),

C-122 (2012), C-255 (2012), C-296 (2012), C-331 (2012), C-383 (2012),

C-540 (2012), C-605 (2012), C-606 (2012), C-609 (2012), C-640 (2012),

C-644 (2012), C-710 (2012), C-715 (2012), C-718 (2012), C-744 (2012),

C-783 (2012), C-847 (2012), C-910 (2012), C-011 (2013), C-54 (2013), C-66 (2013), C-258 (2013), C-330 (2013);SU-388 (2005), SU-62 (2010), SU-446 (2011), SU-897 (2012), SU-1073 (2012), SU-70 (2013), SU-132 (2013), SU254 (2013), T-006 (1992), T-008 (1992), T-414 (1994), T-116 (1995), T-347 (1996), T-393 (1997), T-618 (1998), T-412 (1999), T-1531 (2000), T-1320 (2001), T-1084 (2002), T-1191 (2003), T-1236 (2004), T1331 (2005), T1080 (2006), T-1097 (2007), T-1264 (2008), T-973 (2009), T-1059 (2010), T-981 (2011), T-1095 (2012), T-362 (2013), T-736 (2013), T-043 (2014).

Cortés, J. (2007). La naturaleza jurídica de los derechos económicos, sociales y culturales en la jurisprudencia de la Corte Constitucional. Estudios Socio-Jurídicos, 9(número especial), 109-141.

Dworkin, R. (2005). El imperio de la justicia: de la teoría general del derecho, de las decisiones e interpretaciones de los jueces y de la integridad politica y legal como clave de la teoría y práctica. Barcelona: Gedisa.

Fraser, N. y Honneth, A. (2003). ¿Redistribución o reconocimiento?: un debate politicofilosófico. Madrid: Morata.

Gargarella, R. (1999a). Derecho y grupos desaventajados. Barcelona: Gedisa.

Gargarella, R. (1999b). Las teorías de la justicia después de Rawls. Barcelona: Paidós. Hart, H. (1941). El concepto del derecho. Buenos Aires: Abeledo Perrot.

Honneth, A. (1992). La lucha por el reconocimiento: por una gramática moral de los conflictos sociales. Barcelona: Crítica-Grijalbo Mondadori.

Hunt, A. y Wickham, G. (1994). Foucault and law: Towards a sociology of law as gobernance. London: British Library.

Kelsen, H. (1934). La teoría pura del derecho. Madrid: Trotta.

Kiper, C. (1998). Derechos de las minorías ante la discriminación. Buenos Aires: Hammurabi.

Leiter, B. (2012). Naturalismo y teoría del derecho. Madrid: Marcial Pons.

Lindahl, H. (2007). Constituent power and reflexive identity: Towards an ontology of collective selfhood. En N. Walker y M. Loughlin, The paradox of constitutionalism (pp. 9-24). Oxford: Oxford University Press. 
López, D. (2008). La letra y el espíritu de la ley: reflexiones pragmáticas sobre el lenguaje del derecho y sus métodos de interpretación. Bogotá: Temis.

Mill, J. (1980). El utilitarismo. Buenos Aires: Orbis.

Presidencia de la República de Colombia. 757 (1972), 256 (1973), 1923 (1978), 2217 (1982), 1586 (1989), 775 (1990), 1843 (1991), 36 (1992), 37 (1992), 1088 (1993), 2381 (19939, 24 (1994), 1279 (1994), 82 (1996), 3115 (1997), 24 (1998), 636 (1998), 2647 (1999), 1729 (2002), 3210 (2002), 3232 (2002), 50 (2003), 1747 (2003), 3770 (2003), 4003 (2004), 4360 (2004), 250 (2005), 4686 (2005), 3391 (2006), 4580 (2006), 3600 (2007), 4965 (2007), 3905 (2008), 1997 (2009), 4550 (2009), 4735 (2009), 126 (2010), 433 (2010), 1740 (2010), 2957 (2010), 4803 (2010), 4817 (2010), 1490 (2011), 4065 (2011), 4100 (2011), 4629 (2011), 4633 (2011), 4634 (2011), 4635 (2011), 4800 (2011), 4801 (2011), 4944 (2011), 445 (2012), 2715 (2012), 34 (2013), 48 (2013), 211 (2013), 442 (2013), 722 (2013), 1987 (2013), 1988 (2013), 2210 (2013), 2766 (2013), 2852 (2013), 3036 (2013), 20 (2014), 25 (2014), 64 (2014), 901 (2014).

Rawls, J. (1986). Justicia como equidad: materiales para una teoría de la justicia. Madrid: Tecnos.

Rawls, J. (2006). Teoría de la justicia. México: Fondo de Cultura Económica.

Raz, J. (2007). Una discusión sobre la teoría del derecho. Madrid: Marcial Pons.

Raz, J. (2011). El concepto de sistema jurídico: una introducción a la teoría del sistema jurídico. México: Coyoacán.

Sen, A. (2000). Desarrollo y libertad. Bogotá: Planeta.

Twining, W. (2003). Derecho y globalización. Bogotá: Siglo del Hombre.

Waluchow, W. (2007). Positivismo jurídico incluyente. Madrid: Marcial Pons.

Young, I. (2003). Justicia y política de la diferencia. Bogotá: Ediciones Uniandes.

Uprimny, R. y Guzmán, D. (2010). En búsqueda de un concepto transformador y participativo para las reparaciones en contextos transnacionales. Internacional Law, Revista Colombiana de Derecho Internacional (17), 232-286. 